\title{
Deletion of the Nonribosomal Peptide Synthetase Gene nps 1 in the Fungus Clonostachys rosea Attenuates Antagonism and Biocontrol of Plant Pathogenic Fusarium and Nematodes
}

\author{
Mudassir Iqbal, ${ }^{1, \dagger}$ Mukesh Dubey, ${ }^{1}$ Anders Broberg, ${ }^{2}$ Maria Viketoft, ${ }^{3}$ Dan Funck Jensen, ${ }^{1}$ and Magnus Karlsson ${ }^{1}$ \\ ${ }^{1}$ Department of Forest Mycology and Plant Pathology, Uppsala BioCenter, Swedish University of Agricultural Sciences, 75007 Uppsala, \\ Sweden \\ 2 Department of Molecular Sciences, Uppsala BioCenter, Swedish University of Agricultural Sciences, Uppsala, Sweden \\ ${ }^{3}$ Department of Ecology, Swedish University of Agricultural Sciences, 75007 Uppsala, Sweden \\ Accepted for publication 21 May 2019.
}

\begin{abstract}
Secondary metabolites produced by biological control agents may influence the outcome of their interactions with plant pathogenic microorganisms and plants. In the present study, we investigated the role of the nonribosomal peptide synthetase gene npsl expressed by the biocontrol fungus Clonostachys rosea. A gene expression analysis showed that npsl was induced during confrontations with the plant pathogenic fungus Botrytis cinerea. Gene deletion strains of nps 1 displayed increased growth rates and conidiation. However, the nematicidal activity of culture filtrates from $C$. rosea $\Delta n p s 1$ strains was signi ficantly weaker than that from wild-type filtrates $(P \leq 0.001)$; after $24 \mathrm{~h}$ of incubation with culture filtrates from $n p s l$ deletion strains, only 13 to $33 \%$ of a mixed community of nematodes were dead compared with $42 \%$ of nematodes incubated with wild-type culture filtrates. The $\Delta n p s 1$ strains
\end{abstract}

ABSTRACT also showed reduced biocontrol efficacy during pot experiments, thus failing to protect wheat seedlings from foot rot disease caused by the plant pathogenic fungus Fusarium graminearum. Furthermore, C. rosea $\Delta n p s 1$ strains were not able to reduce populations of plant-parasitic nematodes in soil or in roots of wheat as efficiently as the wild-type strain. Both $C$. rosea wild-type and $\Delta n p s 1$ strains increased the dry shoot weight and shoot length of wheat by 20 and $13 \%$, respectively. We showed that NPS1, a putative nonribosomal peptide synthetase encoded by $n p s 1$, is a biocontrol factor, presumably by producing a hitherto unknown nonribosomal peptide compound with antifungal and nematicidal properties that contributes to the biocontrol properties of $C$. rosea.

Keywords: antagonism, plant growth, wheat
Nonribosomal peptide synthetases (NRPSs) are multifunctional, modular, megasynthases that have a role in the biosynthesis of small bioactive nonribosomal peptides (NRPs) because of their thiotemplate mechanism that is independent of the ribosomal protein synthesis machinery (Finking and Marahiel 2004; Grünewald and Marahiel 2006; Mootz et al. 2002; Reiber et al. 2005; Sieber and Marahiel 2003; Stein et al. 1996). NRPSs synthesize peptides using modules, with each module responsible for incorporating a specific amino acid in the final peptide product. Each module typically contains at least three core domains: an adenylation domain, a thiolation or peptidyl carrier protein domain, and a condensation domain. The adenylation domain recognizes and activates the substrate by using ATP as an energy source (Conti et al. 1997; May et al. 2002; Stachelhaus et al. 1999). The thiolation or peptidyl carrier protein domain accepts the activated substrate, which is bound to a 4'-phosphopantetheine cofactor as a thioester bond (Weber et al. 2000), and it transfers the substrate to a condensation domain, which is responsible for the peptide bond formation between adjacent substrates on the megasynthase complex (Finking

†Corresponding author: M. Iqbal; mudassir.iqbal@slu.se

Funding: The authors thank the Swedish Research Council for Environment, Agricultural Sciences, and Spatial Planning (FORMAS) (grant number 220-2014289), and the Plant Protection Platform and the Centre for Biological Control (CBC) at the Swedish University of Agricultural Sciences for financially supporting this study.

*The $e$-Xtra logo stands for "electronic extra" and indicates that six supplementary figures are published online.

The author(s) declare no conflict of interest.

(C) 2019 The American Phytopathological Society and Marahiel 2004; Keating et al. 2000, 2002; Weber et al. 2000). To date, numerous NRPS genes ( $n p s$ ) have been reported, mostly from bacteria and filamentous fungi, although their biological functions are mostly unknown (Bushley and Turgeon 2010; Oide et al. 2006). However, in past decades, a few functional studies have shown that NRPSs have roles in bacteria and fungi that are related to cell surface properties, morphological and reproductive development, nutrient acquisition, virulence, and protection against oxidative stress (Hahn and Dubnau 1991; Kim et al. 2007; Lee et al. 2005; Oide et al. 2006, 2007). Biotechnological applications have been described, with several NRPSs used as antibiotics or anticancer agents (e.g., bacitracin, gramicidin, penicillin, and vancomycin) and immunosuppressing agents (e.g., rapamycin and cyclosporine) (Challis et al. 2000; Keating et al. 2001; Keating and Walsh 1999; Marahiel et al. 1997; Schaeffer 1969).

The ascomycete Clonostachys rosea (Link: Fr.; Schroers, Samuels, Seifert \& W. Gams, comb. nov.) (Schroers et al. 1999) is a mycoparasitic fungus that can control plant diseases caused by an extensive range of pathogenic fungi, such as Alternaria spp. (Jensen et al. 2004), Bipolaris sorokiniana (Jensen et al. 2002), Botrytis cinerea (Sutton et al. 1997), Fusarium culmorum (Jensen et al. 2000), Fusarium graminearum (Hue et al. 2009), and Sclerotinia sclerotiorum (Rodríguez et al. 2011). However, recent studies have shown that certain $C$. rosea strains also have a negative impact on a range of different plant-parasitic nematodes (Iqbal et al. 2018b; Zou et al. 2010a, b). Several different biocontrol mechanisms have been reported for $C$. rosea, including direct parasitism (Li et al. 2002; Yu and Sutton 1997), antibiosis through the production of secondary metabolites and enzymes (Dong et al. 2005; Dubey et al. 2014; Fatema et al. 2018; Gan et al. 2007; Iqbal et al. 2018b; Pachenari and Dix 1980; Rodríguez et al. 2011; Tzelepis et al. 2015; Zou et al. 2010b), plant growth promotion 
(Ravnskov et al. 2006; Roberti et al. 2008), and the induction of plant defense reactions (Lahlali and Peng 2014; Mouekouba et al. 2014; Roberti et al. 2008).

The genome of $C$. rosea strain IK726 was recently sequenced (Karlsson et al. 2015) and shown to contain high numbers of genes putatively involved in the biosynthesis of natural products, including polyketides and NRPs, but a comparatively low number of chitinases (Tzelepis et al. 2015). Strain IK726 is an efficient biocontrol agent against many plant pathogenic fungi and oomycetes (Jensen et al. 2007) and plant-parasitic nematodes (Iqbal et al. 2018a). The IK726 genome contains 17 nps genes, including the npsl gene, which was predicted to encode an epipolythiodiketopiperazine (ETP) synthetase (Karlsson et al. 2015), which is possibly involved in the biosynthesis of nematicidal epipolysulfanyldioxopiperazine compounds (Dong et al. 2005) or glioperazine (Usami et al. 2004). ETPs are derivatives of cyclic peptides and constitute a poorly studied class of secondary metabolites (Gardiner and Howlett 2005). They typically contain disulfide bridges that allow ETPs to cross-link with proteins via cysteine residues and produce reactive oxygen species (Patron et al. 2007).

This study was designed to characterize the biological function of the $C$. rosea nps 1 gene. We hypothesized that NPS1, a nonribosomal peptide synthetase encoded by $n p s 1$, is involved in the biosynthesis of compounds with antifungal and/or nematicidal activity that contribute to the biocontrol properties of $C$. rosea. By generating C. rosea nps1 deletion strains, we demonstrated that NPS1 plays a role in growth, conidiation, in vitro antagonism against nematodes, and the biocontrol of Fusarium foot rot disease and nematode root diseases of wheat.

\section{MATERIALS AND METHODS}

Fungal strains and maintenance conditions. $C$. rosea strain IK726 (wild-type [WT]) and mutants derived from the WT, B. cinerea strain B05.10, F. graminearum strain $\mathrm{PH}-1$, and Rhizoctonia solani strain SA1 were maintained on potato dextrose agar (PDA) medium (Oxoid; Basingstoke, Hampshire, England) at $25^{\circ} \mathrm{C}$ in the dark. Petri plates with PDA were inoculated using stock cultures preserved in $10 \%$ (wt/vol) glycerol at $-80^{\circ} \mathrm{C}$.

Sequence and phylogenetic analyses. The $n p s 1$ gene was retrieved from the $C$. rosea IK726 genome sequence (EMBL accession no. PRJEB4200) (Karlsson et al. 2015). Conserved protein domains were identified using the Conserved Domain Database (Marchler-Bauer et al. 2017) and Simple Modular Architecture Research Tool (SMART), which is database used for protein prediction (Letunic and Bork 2018). SignalP version 4.1 was used to identify signal peptides for targeting proteins to the secretory pathway (Nielsen 2017).

A reference set of fungal NRPS protein sequences was retrieved for the phylogenetic analysis (Bushley and Turgeon 2010). Adenylation and condensation domains were predicted using SMART (Letunic and Bork 2018). Adenylation and condensation domain sequences were extracted and aligned separately using Clustal W, and a phylogenetic tree was constructed using MEGA version 6 (Tamura et al. 2013). The evolutionary history of NRPS families based on adenylation and condensation domains was inferred using a maximum likelihood method based on the Le and Gascuel (LG) model, and the G + F (gamma distribution with amino acid frequencies) amino acid substitution model (Le and Gascuel 2008) was identified as optimal for modeling gamma rates distributed among sites and partial deletions of gaps for adenylation while using all sites to construct a condensation domain-based phylogenetic tree. Statistical support was determined by $1,000-$ iteration bootstrap resampling.

Experimental setup for gene expression analysis. $C$. rosea $n p s 1$ gene expression was assessed during fungal-fungal interactions using quantitative reverse-transcription PCR (qRT-PCR).
$C$ rosea was confronted in a dual-plate assay with $B$. cinerea $(\mathrm{Cr}-\mathrm{Bc}), F$. graminearum $(\mathrm{Cr}-\mathrm{Fg})$, or with itself $(\mathrm{Cr}-\mathrm{Cr})$ on $9-\mathrm{cm}$ diameter Petri plates containing PDA. Cultures were incubated at $25^{\circ} \mathrm{C}$ in darkness. C. rosea was inoculated 5 days before inoculating $B$. cinerea or $F$. graminearum to compensate for differences in the mycelial growth rate. The growing front ( 7 to $10 \mathrm{~mm}$ ) of the $C$. rosea mycelium was harvested at the time of contact with $B$. cinerea or $F$. graminearum mycelia. Mycelium harvested at the same stage when $C$. rosea confronted itself served as the control treatment. Each treatment was replicated five times.

Nucleic acid isolation and manipulation. Genomic DNA was extracted from $C$. rosea as described previously (Nygren et al. 2008). RNA extraction was performed using a Qiagen RNeasy kit according to the manufacturer's instructions (Qiagen, Hilden, Germany). RNA was treated with RNase-free DNase I (Fermentas, St. Leon-Rot, Germany), and the concentration was determined spectrophotometrically using a NanoDrop-1000 (Thermo Scientific, Wilmington, DE). One microgram of total RNA was reversetranscribed in a total volume of $20 \mu \mathrm{l}$ using the Maxima first strand cDNA synthesis kit (Fermentas, St. Leon-Rot, Germany), followed by 12 -fold dilution and storage at $-20^{\circ} \mathrm{C}$. The following protocol was used for reverse-transcription: $5 \mathrm{~min}$ at $25^{\circ} \mathrm{C}$ and $30 \mathrm{~min}$ at $42^{\circ} \mathrm{C}$, followed by enzyme inactivation at $85^{\circ} \mathrm{C}$ for $5 \mathrm{~min}$.

Gene expression analysis using qRT-PCR. Specific PCR primers targeting the $C$. rosea nps 1 gene (Table 1 ) were designed using the PrimerSelect software implemented in the DNASTAR Lasergene version 10 software package (DNASTAR Inc., Madison, WI). Primer amplification efficiency was determined based on the amplification of serial dilutions of $C$. rosea genomic DNA. Transcript levels were quantified using an iQ5 qPCR system (Bio-Rad, Hercules, CA) using the SsoFast EvaGreen Supermix (Bio-Rad) as described previously (Kamou et al. 2016). Subsequent to the quantitative PCR reactions, a melt curve analysis was performed to confirm that the signal was the result of a single product amplification. Relative expression levels of the npsl gene were calculated in relation to the reference gene $\beta$-tubulin (tub2) (Mamarabadi et al. 2008) using the $2^{-\Delta \Delta C T}$ method (Livak and Schmittgen 2001) with five biological replicates, each based on two technical replicates.

TABLE 1. List of primers used in this study

\begin{tabular}{|c|c|c|}
\hline Name & Target gene ${ }^{a}$ & Sequences $\left(5^{\prime} \rightarrow 3^{\prime}\right)$ \\
\hline Tub CF & $t u b 2$ & ttc aga ccg gtc agt $g \operatorname{ca}^{\mathrm{b}}$ \\
\hline Tub CR & & gcc aga aag cag ca caa $t^{b}$ \\
\hline actin_F & actin & gtt ctg gat tcc ggt gat ggt gtc \\
\hline actin_R & & tcg gca gtg gtg gag aag gtg t \\
\hline NPS1-ups F & nps1 & $\frac{\operatorname{gggg} \text { aca act ttg tat aga aaa gtt } g \text { att gtt }}{\text { gtc } \operatorname{cgc} \operatorname{cgc} \text { ttt gat }{ }^{c}}$ \\
\hline NPS1-ups R & & $\frac{\operatorname{gggg~ac} \operatorname{tgc} t t t \text { tt gta caa act tg ggg caa }}{\text { ata gct } \operatorname{cgc} \text { aca aat }{ }^{\mathrm{c}}}$ \\
\hline NPS1-ds F & nps1 & $\frac{\text { gggg aca gct ttc ttg tac aaa gtg g ccc tga }}{\text { caa tgg aac } \mathrm{cta}^{\mathrm{c} \mathrm{c}^{\mathrm{c}}}}$ \\
\hline NPS1-ds R & & $\frac{\operatorname{gggg} a c \text { aac ttt gta taa taa agt tg ggt gac }}{\text { tgc ttt ggt ttt tag agc }}$ \\
\hline NPS-ko F & npsl & tcg ggt tta gta cgc tga gga a \\
\hline NPS-ko R & & gaa agt ccg ggc gaa caa ac \\
\hline Hyg F & $h p h$ & $\operatorname{gcg} \operatorname{cgc}$ aat taa ccc tca $c^{\mathrm{b}}$ \\
\hline Hyg R & & gaa ttg cgc gta cag aac tcc ${ }^{b}$ \\
\hline HygF_qPCR & $h p h$ & acg gcg gga gat gca ata ggt $^{\mathrm{b}}$ \\
\hline HygR_qPCR & & gct tcg atg tag gag ggc gtg $g^{\mathrm{b}}$ \\
\hline NPS1 F_val & nps1 & get tcg ccc caa ccg taa gag a \\
\hline NPS1 R_val & & agt cgg caa tca cat ggg agg taa $g$ \\
\hline NPS1 F_exp & nps1 & ggc gag ccc ttt tcc aat cc \\
\hline NPS1 R_exp & & aac cca gac caa cgc cca tac taa \\
\hline
\end{tabular}

a $t u b 2=\beta$-tubulin, $h p h=$ hygromycin $\mathrm{B}$ phosphotransferase, $n p s 1=$ nonribosomal peptide synthetase.

b $t u b 2$ primers and $h p h$ primers (from Mamarabadi et al. 2008 and Dubey et al. 2016, respectively).

c attB and attBr sequences are underlined. 
Construction of gene deletion cassette, transformation, and mutant validation. A three-fragment multisite gateway cloning system (Invitrogen, Carlsbad, CA) was used to construct an $n p s 1$ gene deletion cassette. PCR amplification $\approx 1 \mathrm{~kb}$ of the $5^{\prime}$ flank and the $3^{\prime}$ flank regions of the nps 1 gene was performed using $C$. rosea genomic DNA using the gene-specific primer pairs NPS1-ups F/ups R and NPS1-ds F/ds-R (Table 1), respectively, as described in Figure 1. Gateway entry clones of the purified 5' flank and $3^{\prime}$ flank PCR fragments were generated according to the manufacturer's instructions (Invitrogen). We used a gateway entry clone for the hygromycin-resistance cassette (hygB) that was constructed during our previous studies (Dubey et al. 2012, 2013a,b). The gateway LR recombination reaction was performed using the entry plasmid of the respective fragments and the

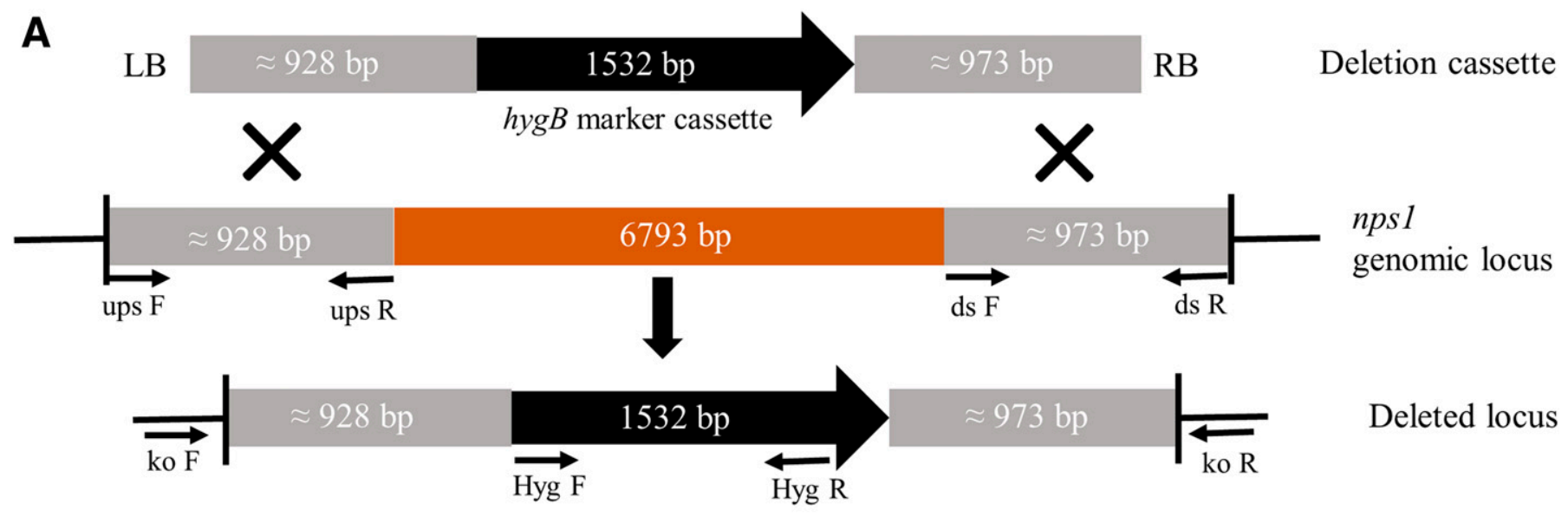

B $\approx 2650$ NPS1-ko F /Hyg R

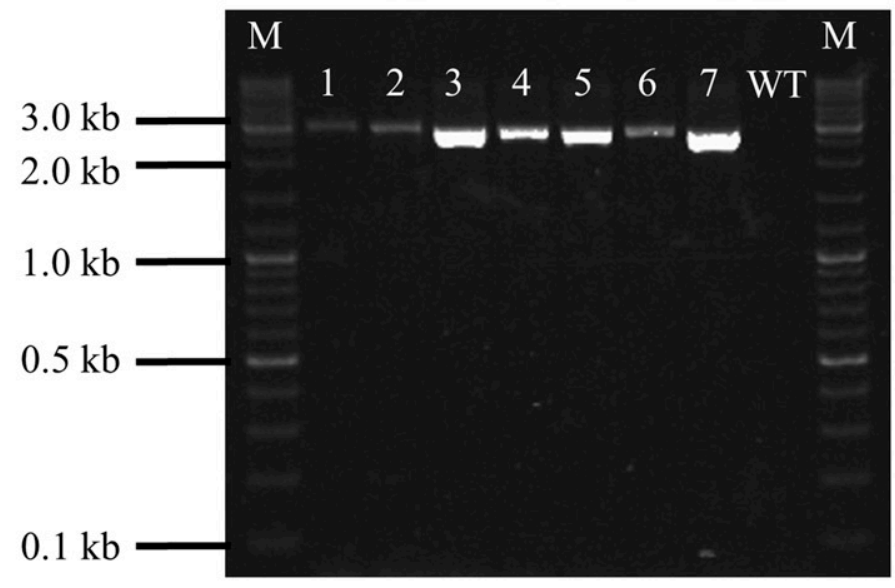

D $\approx 165$ NPS1 F_val / NPS1 R_val

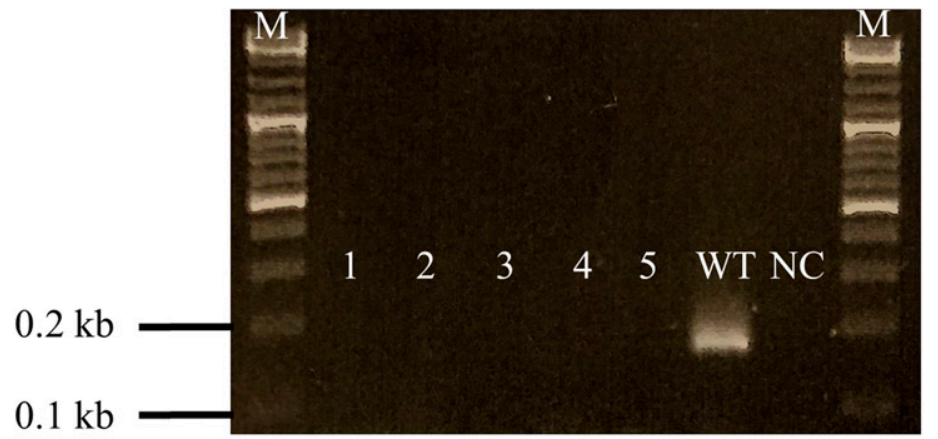

C $\approx 2900$ NPS1-ko R/Hyg F

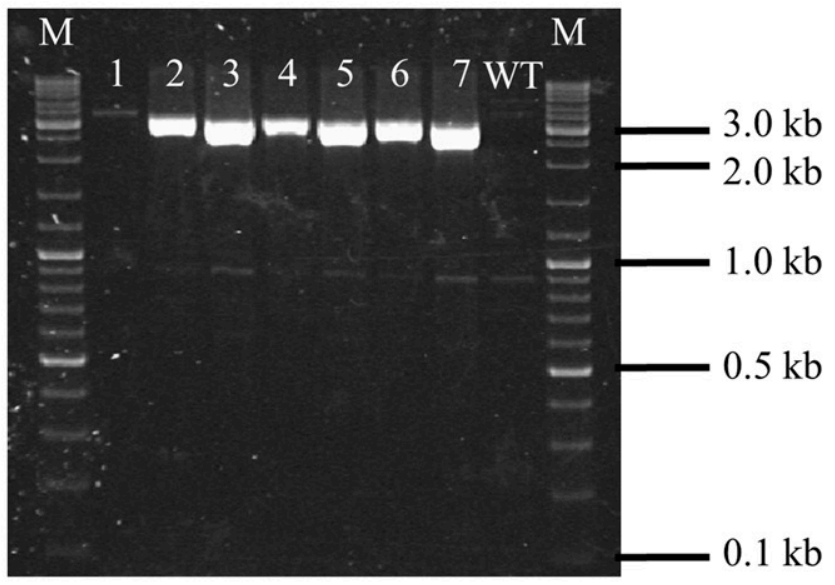

E $\approx 165$ Hyg F_qPCR / Hyg R_qPCR

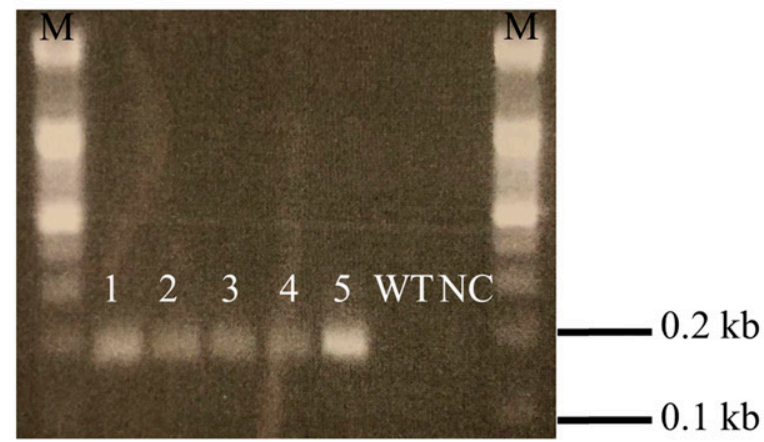

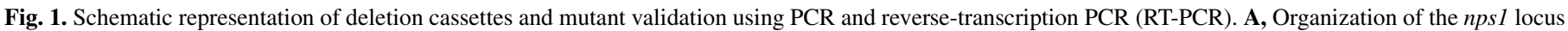

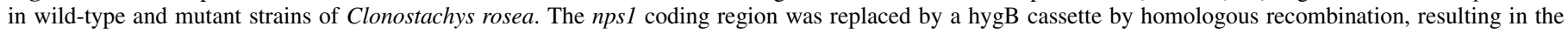

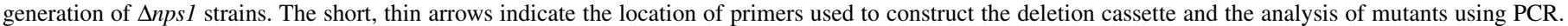

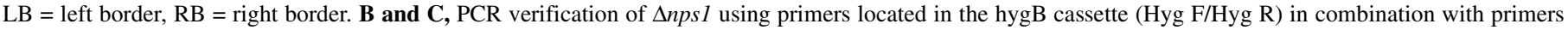

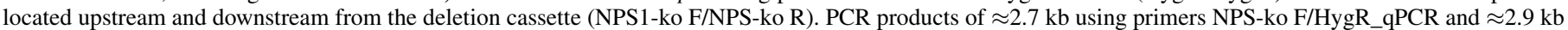

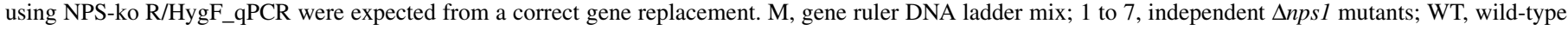

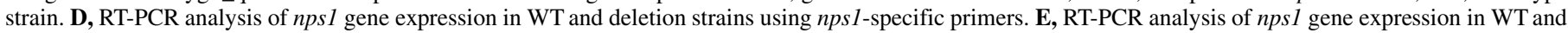

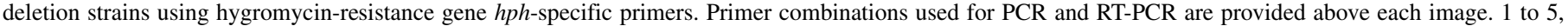
independent $\Delta$ nps 1 mutants used in all phenotypic analyses; $\mathrm{NC}=$ negative control. 
destination vector $\mathrm{pPm} 43 \mathrm{GW}$ (Karimi et al. 2005) to generate a deletion cassette following the conditions described by the manufacturer (Invitrogen).

C. rosea was transformed using Agrobacterium tumefaciensmediated transformation (ATMT) as described previously (Utermark and Karlovsky 2008). Putative transformants were selected and subcultured on PDA plates containing hygromycin $(200 \mu \mathrm{g} / \mathrm{ml})$. To validate the homologous integration of the deletion cassette into putative transformants, a PCR screening approach was performed with primer combinations specific to the hygB cassette (Hyg F/Hyg R) and sequences flanking the deletion vector (NPS1ko F and NPS1-ko R) (Table 1), as described previously (Dubey et al. 2014, 2016). An RT-PCR analysis was performed for C. rosea WT and nps 1 deletion strains using a Maxima first-strand cDNA synthesis kit (Fermentas, St. Leon-Rot, Germany) and primers specific for nps1 (NPS1 F_val and NPS1 R_val), the hygromycinresistance gene $h p h$ (HygF_qPCR and HygR_qPCR), and actin (act; ActinF_qPCR and ActinR_qPCR) (Table 1). PCR-positive transformants were tested for mitotic stability, and then purified by two rounds of single spore isolation, as described previously (Dubey et al. 2014, 2016). The length of the nps 1 gene prevented the construction of a gene complementation cassette; therefore, all phenotypic analyses were performed using five independent positive transformants to ensure that any phenotypic effect was caused by the $n p s 1$ gene deletion, not by ectopic insertions.

Phenotypic analyses of nps 1 deletion mutants. Growth and conidiation rates. To obtain growth rate measurements for C. rosea $\Delta$ nps 1 strains and WT, a 5-mm-diameter agar plug excised from the mycelial front was transferred to PDA and Czapek Dox agar (CZ; Sigma-Aldrich, Steinheim, Germany) plates. Cultures were incubated at $25^{\circ} \mathrm{C}$ under dark conditions, and the colony diameter was measured daily up to 7 days postinoculation (DPI), with three replicates of each isolate. To determine conidiation rates of the $\Delta n p s 1$ strains and WT, conidia were harvested from 13-dayold cultures maintained on PDA and $\mathrm{CZ}$ plates at $25^{\circ} \mathrm{C}$ under darkness by adding $7 \mathrm{ml}$ of sterile water to the culture and then scraping the surface of the mycelium with a glass rod to release the conidia. Conidia were counted using a hemocytometer (Hausser Scientific, Horsham, PA), with four biological replicates of each isolate.

In vitro antagonism assays. The in vitro antagonistic ability of $C$. rosea $\Delta n p s l$ strains and WT against $B$. cinerea and $F$. graminearum was determined by performing a dual-plate confrontation assay. A 9-cm PDA plate was inoculated with a 5mm-diameter mycelial agar plug of a $C$. rosea strain on one side of the plate. After 7 days of incubation at $25^{\circ} \mathrm{C}$ in darkness, an agar plug of B. cinerea or $F$. graminearum was inoculated at an equal distance on the opposite side of the plate, and mycelial growth was measured daily for up to 5 DPI.

Mycelial biomass production, the production of fungal growthinhibiting compounds, and nematicidal inhibition levels in liquid cultures of $C$. rosea $\Delta n p s l$ strains and WT were measured by inoculating $100 \mathrm{ml}$ of potato dextrose broth (PDB) in 500-ml Eflasks with $2 \times 10^{6}$ conidia/flask of $C$. rosea $\Delta$ nps 1 strains or WT, followed by incubation at $25^{\circ} \mathrm{C}$ on a rotating shaker $(120 \mathrm{rpm})$ for 2 weeks under dark conditions. The fungal biomass was separated from the broth by filtering it through three layers of filter paper (Ahlstrom-Munksjö, Helsinki, Finland). The culture filtrate was further sterile-filtrated through a $0.45-\mu \mathrm{m}$ cellulose membrane (Sarstedt, Nümbrecht, Germany), as described previously (Iqbal et al. 2018b). Subsequently, $10 \mathrm{ml}$ of culture filtrate was transferred to a 50-ml E-flask and inoculated with a 5-mm-diameter agar plug from a 3-day-old culture of B. cinerea, F. graminearum, or $R$. solani and incubated at $25^{\circ} \mathrm{C}$ on a rotary shaker $(120 \mathrm{rpm})$ in darkness. The dry weight biomass of the plant pathogenic fungi was recorded at 5 DPI.

To determine the level of nematicidal activity, culture filtrate $(800 \mu \mathrm{l})$ or liquid media (control) was mixed with $200 \mu \mathrm{l}$ of water containing 100 nematodes (a mixed community extracted from soil) in wells (in a 24-well plastic plate) and incubated at $25^{\circ} \mathrm{C}$ in darkness for $24 \mathrm{~h}$. The number of viable nematodes was determined by washing the nematodes with cold water and by performing a touch assay under a light microscope (Wild M5A; Heerbrugg, Switzerland) at 50× magnification (Gill et al. 2003).

To examine the involvement of NPS1 during secondary metabolite production, the aforementioned culture filtrates were further analyzed by performing ultra-high-performance liquid chromatography-mass spectrometry (UHPLC-MS). UHPLC-MS analyses were performed using an Agilent 1290 Infinity II UHPLC (Agilent, Palo Alto, CA) attached to a Bruker maXis Impact QTOF MS (Bruker Daltonic GmbH, Bremen, Germany). Samples $(1 \mu \mathrm{l})$ were analyzed on a reversed-phase UHPLC column $(2.1 \times 50 \mathrm{~mm}$, $1.5 \mu \mathrm{m}$; Accucore Vanquish; Thermo Scientific, Waltham, MA) and eluted with a gradient of acetonitrile $(\mathrm{MeCN})$ in water with $0.2 \%$ formic acid (10 to $95 \% \mathrm{MeCN}$ for $3 \mathrm{~min}$ and $95 \% \mathrm{MeCN}$ for $1.2 \mathrm{~min}$ at $0.9 \mathrm{ml} / \mathrm{min}$ ). The MS was used in the positive mode with a range of $\mathrm{m} / z 50$ to 1500 . Compass Data Analysis 4.3 software (Bruker Daltonics) was used to calibrate mass spectra against sodium formate clusters to create extracted ion chromatograms corresponding to expected substances and to convert data to the mzXML format. Ion chromatogram peak picking was conducted using the $\mathrm{R}$ software environment and the XCMS program (Smith et al. 2006) and centWave method (Tautenhahn et al. 2008). All mycelial biomass production measurements, in vitro antagonism assays, and chemical analyses were performed using five biological replicates.

In planta biocontrol assays. The in planta biocontrol ability of snpsl strains and WT were evaluated with two different experiments:

I. A Fusarium foot rot assay on wheat (Triticum aestivum, winter wheat cultivar Stava) was performed using five biological replicates. Each replicate consisted of 12 to 15 plants and followed the procedure described previously (Dubey et al. 2014, 2016; Knudsen et al. 1995). Surface-sterilized wheat seeds were air-dried in a laminar flow cabinet and inoculated with $C$. rosea WT or npsl deletion strain conidia $\left(1 \times 10^{7}\right.$ conidia/ml) during a 30-min period on a rotary shaker (150 rpm). Water-soaked seeds were used as a control. Three seeds were sown in a 2-cm hole in moistened sand in individual plastic pots $(5 \times 5 \times 5 \mathrm{~cm})$. Pathogen inoculation was performed by placing a 5-mm-diameter PDA plug with $F$. graminearum mycelium in the hole close to the seeds (Roberti et al. 2008). A sterile PDA plug without any $F$. graminearum mycelium was used as a control. After inoculation, holes were covered with moist sand. Pots were maintained in a growth cabinet under controlled conditions (i.e., 12-h/12-h light/dark photoperiod with $150 \mu \mathrm{mol} \cdot \mathrm{m}^{-2} \cdot \mathrm{s}^{-1}$ light intensity, temperature of $15^{\circ} \mathrm{C} \pm 1^{\circ} \mathrm{C}$, and relative humidity of $80 \pm 5 \%$ ). Seedlings were harvested 3 weeks postinoculation, and disease symptoms were scored based on a scale of 0 to 4, as described previously (Dubey et al. 2014, 2016; Knudsen et al. 1995).

II. An assay of nematode root disease in wheat was performed with eight biological replicates using naturally infested soil, as described previously (Iqbal et al. 2018b). Briefly, soil was collected in December 2016, from a field in Säby (coordinates: lat. $59^{\circ} 51^{\prime} 10.98^{\prime \prime} \mathrm{N}$, long. $17^{\circ} 40^{\prime} 37.344^{\prime \prime} \mathrm{E}$ ), which is close to Uppsala, Sweden. Soil samples were collected from three distinct locations within a single field during fallow conditions after wheat. Samples were pooled, mixed thoroughly, and maintained in plastic bags at $4{ }^{\circ} \mathrm{C}$ prior to experiments. Immediately before setting-up the experiment, the soil was cleaned to remove clumps and mixed with sand (particle size, $0.50 \mathrm{~mm}$; Rådasand, Lidköping, Sweden) to a final content of $20 \% \mathrm{vol} / \mathrm{vol}$. To formulate C. rosea $\Delta n p s 1$ and WT strains as peat-wheat bran powder formulations, we 
adapted the method described by Jensen et al. (2000) by using a coffee mill. Spore viability and the concentration of $C$. rosea strains in the formulations were determined as described previously (Iqbal et al. 2018b). C. rosea formulations were mixed with soil to reach a final concentration of $2.5 \times 10^{5}$ viable $\mathrm{CFU} / \mathrm{g}$ of soil. Plastic pots $(9 \times 9 \times 10 \mathrm{~cm})$ were filled with $480 \mathrm{~g}$ of C. rosea-inoculated or uninoculated soil (control). Eight wheat seeds were planted in each pot and placed in a growth cabinet with a 12-h/12-h light/dark photoperiod at $15^{\circ} \mathrm{C}$ and relative humidity of $70 \pm 5 \%$. All pots were subjected to the same watering regime throughout the 8-week experimental period.

At the end of the experiment, plants were harvested by cutting aerial parts at the root-shoot junction at the surface of the soil, and plant shoot dry weight $(\mathrm{g})$ and shoot length $(\mathrm{cm})$ were recorded. Living nematodes were extracted from $15 \mathrm{~g}$ of soil and $1 \mathrm{~g}$ of harvested roots using a modified Baermann funnel method (Baermann 1917; Viketoft et al. 2005). Counting of the number of nematodes was conducted under a light microscope (Wild M5A; Heerbrugg, Switzerland). The classification of nematodes to the genus level was based on an analysis of morphological characters. Reliable and nonoverlapping morphological characters, such as the type of body cuticle, labial regions (e.g., amphidial apertures and stylet), pharynx and tail shape, and the position of the excretory and nerve ring were considered. The male and female reproductive system characters were also considered during identification (Decraemer and Hunt 2013; Hunt et al. 2018).

Statistical analyses. Gene expression and phenotypic data were analyzed using an analysis of variance (ANOVA) with a general linear model approach implemented in Minitab Statistical Software version 18.1 (Minitab Inc., State College, PA). Pairwise comparisons were performed using Fisher's least significant difference or the Tukey-Kramer method at the $95 \%$ significance level. Statistical analyses of the UHPLC-MS data were performed using MetaboAnalyst 4.0, a web-based tool suite for metabolomic data analysis (Chong et al. 2018). After sample normalization by sum, log transformation, and Pareto scaling (division by the square root of the respective standard deviation) (van den Berg et al. 2006), differences between sample groups (mutants and WT) were analyzed using a principal component analysis and orthogonal partial least squares discriminant analysis, along with ANOVA or $t$ tests.

\section{RESULTS}

Sequence analysis of $\boldsymbol{n p s} 1$. The full-length sequence of $n p s 1$ was retrieved from the genome of the C. rosea strain IK726 (Karlsson et al. 2015). The open reading frame of $n p s 1$ was $6621 \mathrm{bp}$ (excluding three introns of 56, 55, and $60 \mathrm{bp}$ ) and was predicted to encode a polypeptide composed of 2206 amino acid residues (protein ID: BN8691_T00013362_1). The conserved domain and SMART protein analysis of the translated amino acid revealed that the NPS1 protein was composed of three parts, i.e., an adenylation or AMP-binding domain (amino acid positions 1078 to 1461), a thiolation or phosphopantetheine attachment site (amino acid positions 1584 to 1647), and a condensation domain (amino acid positions 1673 to 1955 ). A SignalP analysis did not identify an Nterminal secretion signal peptide.

Adenylation domain-based phylogenetic analysis resolved nine major NRPS subfamilies (Fig. 2), as described previously (Bushley and Turgeon 2010). Two adenylation domains were present in the predicted NPS1 protein sequence. The first predicted NPS1 adenylation domain clustered in the ChNPS11/ETP module 1 synthetase subfamily of toxins (e.g., gliotoxin and sirodesmin) with 99\% bootstrap support, whereas the other adenylation domain clustered in the ChNPS12/ETP module 2 subfamily (Fig. 2). More specifically, NPS1 clustered with Afu6g 09660_A1_2 from Aspergillus fumigatus with $96 \%$ bootstrap support (Fig. 2). A phylogenetic analysis using the condensation domains resulted in the same clustering (Supplementary Fig. S1).
Nps1 gene expression analysis. The primer pair NPS1 F_exp and NPS1 R_exp (Table 1) specifically amplified a 177-bp amplicon of the nps 1 gene with PCR amplification efficiency of $90 \%$. The relative expression of the $n p s 1$ gene was 18 -fold higher during confrontations between $C$. rosea and B. cinerea $(P \leq 0.05)$ than that induced by confrontations with $F$. graminearum or the selfconfronting control treatment (Fig. 3).

Generation and validation of nps 1 deletion strains. The npsl gene was replaced with the hygB selection cassette by homologous recombination using ATMT. A total of 470 hygromycin-resistant $C$. rosea colonies were obtained over the course of four independent transformations on selection plates containing cefotaxime $(200 \mu \mathrm{g} / \mathrm{ml})$ and hygromycin $(200 \mu \mathrm{g} / \mathrm{ml})$. After subculturing colonies on fresh selection plates, 430 hygromycin-resistant colonies remained. Successful PCR amplification of products of the expected size using primers located upstream and downstream of the deletion construct in combination with primers located in the hygB cassette (Fig. 1A) was observed for seven $\Delta$ ns l strains, whereas no amplification of the WT was observed (Fig. 1B and C). Furthermore, the RT-PCR analysis confirmed loss of npsl expression in five randomly selected mutants (Anpsl-A, $\Delta n p s 1-\mathrm{B}, \Delta n p s 1-\mathrm{C}, \Delta n p s 1-\mathrm{D}$, and $\Delta n p s 1-\mathrm{E})$, whereas expression was detected in the WT (Fig. 1D). Hph expression was detected in the five $\Delta n p s 1$ strains, whereas no amplification was observed in the WT (Fig. 1E). Successful RTPCR amplification of act in all mutants and WT indicated that the cDNA was intact.

Phenotypic analyses. Deletion of nps1 increased the growth and conidiation rate of $\mathrm{C}$. rosea. The growth rate of all $C$. rosea nps 1 deletion strains was, on average, $21 \%$ higher than the WT growth rate on PDA and $25 \%$ higher on $\mathrm{CZ}(P \leq 0.001)$ (Fig. 4A and B). However, there was no significant difference $(P=0.098)$ in biomass production when npsl deletion strains and WT were cultured in liquid PDB. However, the conidiation of npsl deletion strains was significantly greater $(P \leq 0.001)$ than that of WT when cultured on PDA (average, 203\%) or CZ (average, 87\%) (Fig. 4C and D).

Deletion of $\mathrm{nps} 1$ in $\mathrm{C}$. rosea reduces in vitro antagonism against nematodes. B. cinerea and $F$. graminearum showed reduced growth rates in dual-plate confrontation assays with $C$. rosea WT $(P=0.001)$ compared with their growth rates when grown alone, unchallenged by $C$. rosea WT (Supplementary Fig. S2A). Furthermore, B. cinerea showed a reduced growth rate $(P=$ $0.016)$ at 3 DPI during interactions with npsl deletion strains compared with that observed during interactions with $C$. rosea WT. However, this effect was not statistically significant at 5 DPI. The growth rate of $F$. graminearum was not statistically different in dual-plate assays with WT or $\Delta n p s 1$ strains at 3 or 5 DPI $(P \geq$ 0.12) (Supplementary Fig. S3A). However, a zone of inhibition was observed during interactions with WT at 3 weeks after inoculation, but not during interactions with $\Delta n p s 1$ strains. Additionally, there was no significant difference in the amount of mycelial biomass produced by $B$. cinerea, $F$. graminearum, or $R$. solani when grown in culture filtrates of nps 1 deletion strains compared with that of WT.

The nematicidal activity of culture filtrates from $n p s 1$ deletion strains was significantly weaker than that of WT $(P \leq 0.001)$; after $24 \mathrm{~h}$ of incubation with culture filtrates from $n p s l$ deletion strains, only 13 to $33 \%$ of a mixed community of nematodes were dead compared with $42 \%$ of nematodes incubated with WT culture filtrates (Fig. 5). A closer inspection of the nematode mortality data revealed that the mortality level of plant-parasitic nematode genera (i.e., Pratylenchus, Boleodorus, Merlinus, Rotylenchus, Helicotylenchus, Tylenchorhynchus, Heterodera [juvenile stage, J2], and Paratylenchus) was significantly $(P \leq 0.001)$ higher than that of nonparasitic nematode groups (bacterivores, fungivores, and omnivores) when incubated in culture filtrates of nps 1 deletion strains and WT (Supplementary Fig. S4). 
Known nematicidal dioxopiperazines produced by $C$. rosea (i.e., gliocladin A-E, verticillin A, 11-deoxyverticillin A, Sch52900, and Sch52901) (Dong et al. 2005) were not detected by UHPLC-MS analyses of culture filtrates from $C$. rosea WT and nps 1 mutant strains. Furthermore, an untargeted comparison of the metabolite profiles of $C$. rosea WT and nps 1 mutant strains did not reveal any consistent or significant differences in metabolite profiles (Supplementary Fig. S5).

SID

(e.g., ferrichrome,

ferrichromeA. ferricrocin)

Fg_FGSG05372.3_A1_-

An_AN0607.4A2 _ 3

50 - Um UM01434.1 A2

99-Ch_CocheC5_77609_A2

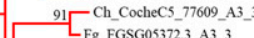

An_AN0607.4_A3_3

97 Fq_FGSG11026.3_A3_3

Af $A$ fun $303350-A 1$

Af_Afusgo3350_A -

Af $A$ fi3 $303350-12$

Af Afu3g15270 A2

Mg MGG07858.

Che CocheC5 54644 A2 2

Ch Cochecs 110280

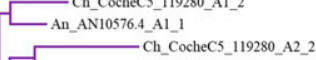

Ch_CocheC5

An_ANG20.4_AI_- 2

Mg_MGG00022.6_Al

Mg_MGG07858.6_A3_4

Ch_CocheC5_94644_Al_2

- Mg_MGG07858.6_A4_4

66 Ch_CocheC5_15959_A3_4

- Ch_CocheC5_15959_A2 - Ch_CocheC5_84777_A1_3 96-Af_Afu6g09660_Al_2 Cr_BN8691_T00013362_A1_2 (NPS1) -Af_Afu3g12920_Al_

4 -Ch_CocheC5_118012_Al Ch_CocheC5_116719_Al_ -Fg_FGSGI1294.3_A2_ Pp_Pospll_42034_Al_1 Pp_Pospli_49678_A1

96-Af_Afu6g09660 A2 2

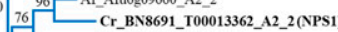

Mg_MGG15248.6_Al_

Af_Afu3g12920_A2_2

-Bd_BDEG08447.1_Al_1 - Bd BDEG03514.A1 Mg_MGG14897.6_Al_1

(e.g., ACE1, equisetin, fusarin C)

ChNPS11/ETP module 1

(e.g., gliotoxin, sirodesmin)

ChNPS12/ETP module 2

20

ChNPS10

Ch_

Af_Afusglo120_Al_1

Um_UM03108.1_Al_1

Mg_MGG03290.6_Al_t

61_Ch_CocheC5_115936_Al

78 - Af_Afutg11240_Al_1

9 -Fg_FGSG06041.3_A1_

-Um_UM01697.1_Al_1

${ }_{54}$-Bd_BDEG01579.1_A1_

[F_FGSG11989.3_Al_1

$90-$ Mg_MGG00022.6_A2 $3{ }^{3}$

—Ch_CocheC5_15959_Al_4

-An_AN9226.4_A2_2

79. Ch_CocheC5_15959_A4_

An_AN2621.4_Al_3

LPCCAA38195.1_AI

Ac_P25464.1_A1_-3

An AN2621.4 A2

Pe CAA38195.1_A2 3

80 [Ac_P25464.1_A2_3

Ni_P27743.

-Ni_P27743.1_A3_3

99 -Ac_P25464.1_A3 3 3

97 -

0.5

Outgroup (e.g., cyclosporine, enniatin)

ACV

(e.g., penicillin, cephalosporin)

Fig. 2. Phylogenetic tree of major NRPS subfamilies based on adenylation domains. Amino acid sequences of NRPSs were retrieved (Bushley and Turgeon 2010). Adenylation domains were predicted using SMART, a protein prediction tool, aligned by Clustal W, and used to construct a phylogenetic tree using a maximum likelihood method in MEGA version 6. Branch support values (bootstrap proportion $\geq 50$ ) are associated with nodes. The nine major subfamilies of NRPS are shown in the tree. The scale bar indicates the branch length measured as the average number of substitutions per site. Ac $=$ Acremonium chrysogenum, Af $=$ Aspergillus fumigatus, $\mathrm{An}=$ Aspergillus nidulans, $\mathrm{Bd}=$ Batrachochytrium dendrobatidis, $\mathrm{Ch}=$ Cochliobolus heterostrophus, $\mathrm{Cr}=$ Clonostachys rosea, $\mathrm{Fg}=$ Fusarium graminearum, $\mathrm{Mg}=$ Magnaporthe oryzae, $\mathrm{Nl}=$ Nocardia lactamdurans $($ bacterium $), \mathrm{Pc}=$ Penicillium chrysogenum, $\mathrm{Pp}=$ Postia placenta, $\mathrm{Tr}=$ Trichoderma reese , and $\mathrm{Um}=$ Ustilago maydis. 
Deletion of nps1 reduces $\mathrm{C}$. rosea biocontrol efficacy against Fusarium foot rot disease. Coating wheat seeds with WT $C$. rosea conidia provided very good protection $(P<0.05)$ against Fusarium foot rot disease caused by $F$. graminearum (Fig. 6). In contrast, all $C$. rosea npsl deletion strains failed $(P>0.05)$ to protect wheat seedlings against the disease (Fig. 6). The disease severity on wheat seedlings grown from seeds coated with $\Delta n p s 1$ strains was higher than that on seedlings grown from seed coated with WT (Fig. 6), although this increase was not significant for strains $\Delta n p s l-\mathrm{B}$ and $\Delta n p s$ l-D. The shoot weight of $\Delta n p s$ l-treated and WT-treated wheat seedlings was not significantly different $(P=0.204)$ (Supplementary Fig. S6).

Deletion of nps1 reduces C. rosea biocontrol efficacy against nematode root disease. The number of nematodes recovered from soil 8 weeks after inoculating the soil with either the $C$. rosea WT or $\Delta$ nps 1 strain was $31 \%$ and 19 to $26 \%$ lower, respectively, than that recovered from the control treatment $(P<0.001)$ (Fig. 7A). Inoculation of soil with $\Delta n p s 1$ strains reduced $(P<0.001)$ the number of recovered nematodes to a significantly lesser degree than the WT treatment (Fig. 7A). The nematode mortality data were then split into two groups comprising plant-parasitic nematode genera (27\% of all nematodes) and nonparasitic nematodes (i.e., bacterivores, fungivores, or omnivores; $73 \%$ of all nematodes). Reanalysis of the data revealed that the number of plant-parasitic nematode genera (Pratylenchus, Boleodorus, and Merlinus) recovered from soil inoculated with $C$. rosea WT was lower $(P<0.05)$ than that recovered from the other soils (Fig. 7B). The same effect was also seen for nonparasitic nematode groups (Fig. 7C), although the effect was less pronounced than it was for the plant-parasitic genera. In contrast, soil inoculated with C. rosea $\Delta n p s 1$ strains reduced the number of plant-parasitic nematode genera that were recovered $(P<0.05)$ (Fig. 7B), but not the numbers of bacterivore, fungivore, and omnivore groups recovered (Fig. 7C).

Furthermore, adding $C$. rosea WT to soil reduced $(P<0.001)$ the number of Pratylenchus (migratory endoparasitic) and Heterodera $\left(\mathrm{J}_{2}\right.$, endoparasitic) nematodes extracted from roots of wheat by $46 \%$ compared with the control treatment (Fig. 8). Although inoculating soil with $n p s 1$ mutant strains reduced $(P<0.001)$ the number of endoparasitic nematodes recovered from wheat roots by $22 \%$

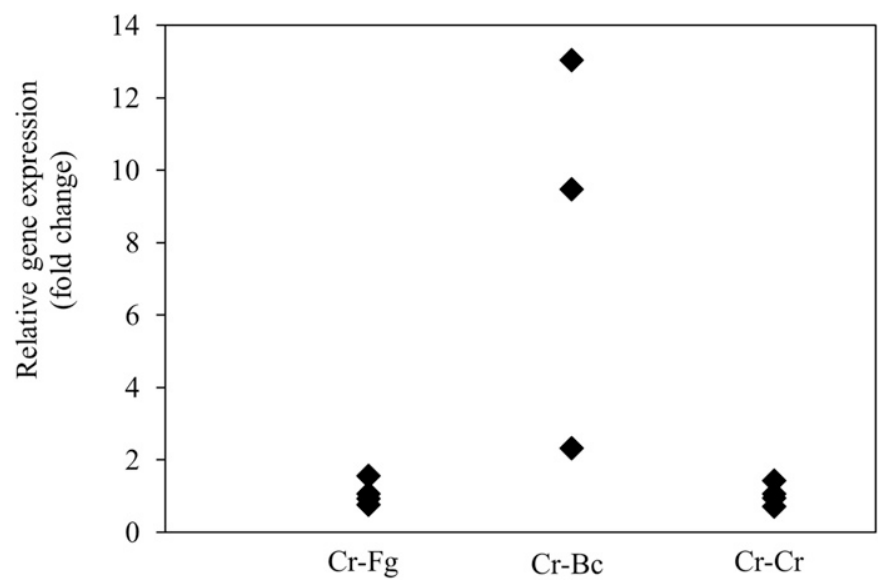

Fig. 3. Expression analysis of $n p s 1$ during interactions with fungal prey. Jitter plot showing gene expression of nps 1 determined by qRT-PCR during the interaction of Clonostachys rosea with Botrytis cinerea $(\mathrm{Cr}-\mathrm{Bc}), C$. rosea with Fusarium graminearum $(\mathrm{Cr}-\mathrm{Fg})$, and $C$. rosea with itself $(\mathrm{Cr}-\mathrm{Cr}$, control). Relative expression is calculated as the ratio between the nps 1 gene and tubulin using the $2^{-\triangle \Delta C T}$ method. Gene expression during the interaction of $\mathrm{Cr}-\mathrm{Bc}$ was significantly higher $(P \leq 0.05)$ than that during the interaction of $\mathrm{Cr}-\mathrm{Cr}$ or $\mathrm{Cr}-\mathrm{Fg}$, as determined by the Tukey-Kramer test. The statistical analysis was performed for a minimum of three biological replicates. One biological replicate in the $\mathrm{Cr}-\mathrm{Cr}$ treatment deviated considerably from the other four replicates and was considered an outlier; therefore, it was excluded from the calculations. compared with the control treatment, the effect of this treatment was less pronounced compared with that of the WT treatment $(P<$ 0.001) (Fig. 8).

Wheat grown in soil inoculated with either $C$. rosea WT or $\Delta n p s 1$ strains showed increased $(P<0.001)$ shoot length $(13 \%)$ and dry shoot weight (20\%) compared with the control treatment (Fig. 9A and B); however, the strain used to inoculate the soil did not significantly affect shoot length or dry shoot weight. In addition, yellowing of leaves and chlorosis were observed in control plants, but not in plants grown in soil treated with $C$. rosea WT or $\Delta n p s 1$ (data not shown).

\section{DISCUSSION}

Out of the 17 NRPS genes in the $C$. rosea genome, nps 1 is the only gene predicted to encode an ETP synthetase (Karlsson et al. 2015), which is further supported by our phylogenetic analysis, which clustered the predicted NPS1 into the ChNPS11/ ETP module 1 and ChNPS12/ETP module 2 subfamilies. The predicted modular structure of NPS 1 contains all the necessary domains (adenylation, thiolation or peptidyl carrier protein, and condensation) that are required for a functional NRPS to perform peptide synthesis (Conti et al. 1997; Keating et al. 2000, 2002; May et al. 2002; Stachelhaus et al. 1999; Weber et al. 2000). The induction of the npsl gene during interactions with $B$. cinerea suggests that NPS1 has a role during interspecific fungal interactions. The gene was also expressed during interactions with $F$. graminearum, although expression was not significantly higher than that induced by the control treatment, which did not contradict a role in mycoparasitism.

Other NRPS genes in mycoparasitic fungi have been reported to be differentially expressed in interspecific fungal interactions; for example, nps 13 in $C$. rosea strain IK726 was induced during confrontations with $B$. cinerea, but not during confrontations with F. graminearum (Nygren et al. 2018). Furthermore, the NRPS-like gene TOPH 03459 in the truffle parasitizing fungus Tolypocladium ophioglossoides was highly upregulated during growth in yeast malt broth compared with broths containing material from the Elaphomyces muricatus truffle host (Quandt et al. 2016). Peptaibols are a large and complex group of NRPs with antibiotic properties that have an important role in antagonism and mycoparasitism in Trichoderma atroviride strain P1 (Lorito et al. 1994, 1996; Schirmböck et al. 1994) and C. rosea (Rodríguez et al. 2011). The npsl gene was also expressed during $C$. rosea self-interactions, which showed that interspecific fungal interactions are not crucial for the transcriptional activation of npsl and may suggest more diverse roles for NPS1.

Furthermore, the deletion of $n p s l$ was associated with an increase in the growth rate and conidiation of $C$. rosea. This suggested that the NPS1 product metabolite(s) may exert an inhibitory effect on $C$. rosea growth. Alternatively, deletion of the nps 1 gene may allow the allocation of resources for growth and conidiation that would otherwise be used for secondary metabolite biosynthesis (Calvo et al. 2002); in other words, there could be a trade-off between investing resources in growth versus secondary metabolite production. Similar results were observed in a study involving the mycoparasitic fungus Trichoderma virens, in which the deletion of tex7, tex8, and tex13 NRPS genes resulted in mutants with higher growth rates compared with that of the WT (Mukherjee et al. 2012). Our results were also in line with those of a previous study that showed that deletion of the polyketide synthase genes pks22 and pks 29 in C. rosea IK726 resulted in increased conidiation (Fatema et al. 2018), suggesting that secondary metabolites may influence the growth and development in C. rosea.

The involvement of NRPSs in fungal growth, morphology, pigmentation, and reproduction has been reported by studies involving the plant pathogen Cochliobolus heterostrophus. Oide et al. (2007) indicated that the $n p s 2$ gene is essential for ascospore 
development in $C$. heterostrophus given that $\Delta n p s 2$ strains failed to form asci or ascospores in crosses where the $\Delta n p s 2$ mutation was homozygous. Furthermore, $C$. heterostrophus $\Delta$ nps6 strains showed a reduction in pigmentation and in asexual sporulation compared with the WT (Oide et al. 2006). However, the lack of severe developmental or morphological defects in C. rosea $\Delta n p s 1$ strains did not support a similar direct involvement of NPS1 in reproduction.

The reduced growth rate of $B$. cinerea during dual-plate interactions with $\Delta n p s 1$ strains compared with the WT at 3 DPI may be associated with the higher growth rate of $\Delta n p s 1$ strains. However, this is only a minor effect because it was not observed at 5 DPI or during interactions with $F$. graminearum. In contrast, the effects of WT versus $\Delta n p s 1$ strains against nematodes were considerable. The lower nematode mortality in culture filtrates from nps 1 deletion strains compared with that from WT suggested that NPS1 biosynthesizes a metabolite with nematicidal properties. Dong et al. (2005) isolated nine verticillin-type epipolysulfanyldioxopiperazine (gliocladin A-E, verticillin A, 11-deoxyverticillin A, Sch52900, and Sch52901) compounds from C. rosea strain 1A, and all compounds showed toxicity toward Caenorhabditis elegans and Panagrellus redivivus nematodes, with $>50 \%$ mortality after $24 \mathrm{~h}$ of incubation. The failure to identify these metabolites in this study may have been attributable to differences in growth conditions (wheat kernels vs. PDB) or between strains. Mining the UHPLC-MS data did not result in identifying the putative NPS1 product metabolite because the detected metabolites were not present in WT; however, they were absent in $\Delta n p s 1$ strains. This may have been attributable to a number of reasons, including the presence of the metabolite at a concentration that was too low for detection in the investigated cultures. Furthermore, growth in PDB may not be optimal for producing the NPS1 product metabolite. Culture filtrates from $\Delta n p s 1$ strains still possessed a certain level of nematicidal activity, which may have been caused by the production of additional compounds or enzymes (e.g., serine proteases) with nematicidal activity. Previously, it was shown that $C$. rosea strain 611 produces the extracellular serine protease $\mathrm{PrC}$ during growth in PDB, which accounted for $80 \%$ mortality of $P$. redivivus within $48 \mathrm{~h}$ of incubation with $\mathrm{PrC}$ ( $\mathrm{Li}$ et al. 2006). Serine protease genes were also induced in $C$. rosea strain IK726 during confrontation with F. graminearum (Iqbal et al. 2018b) and with the silver scurf pathogen of potato Helminthosporium solani (Lysøe et al. 2017), suggesting that serine proteases may be involved in several different biotic interactions.

Interestingly, plant-parasitic nematodes had higher mortality rates in culture filtrates from $C$. rosea compared with nonparasitic

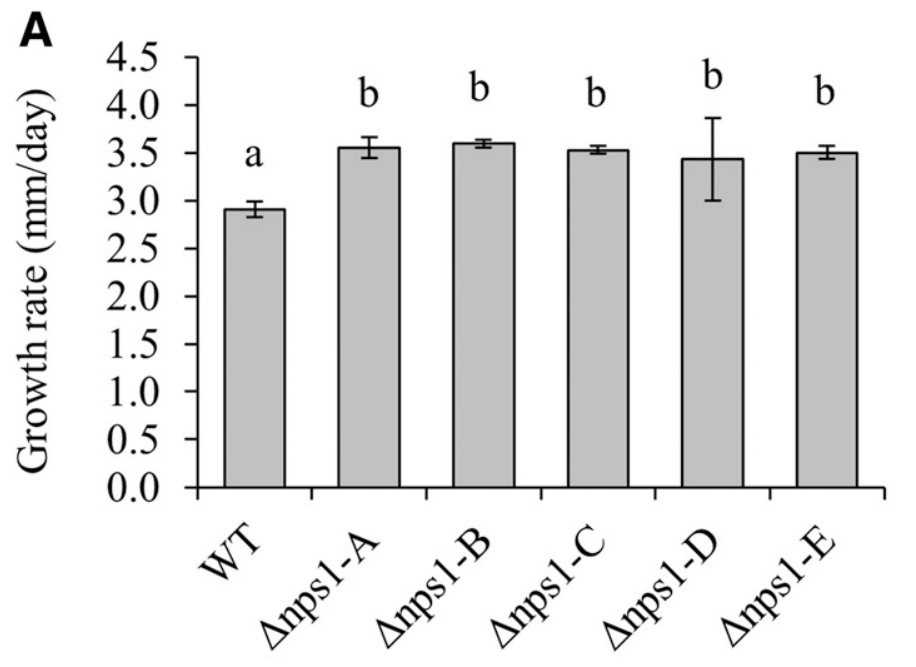

B
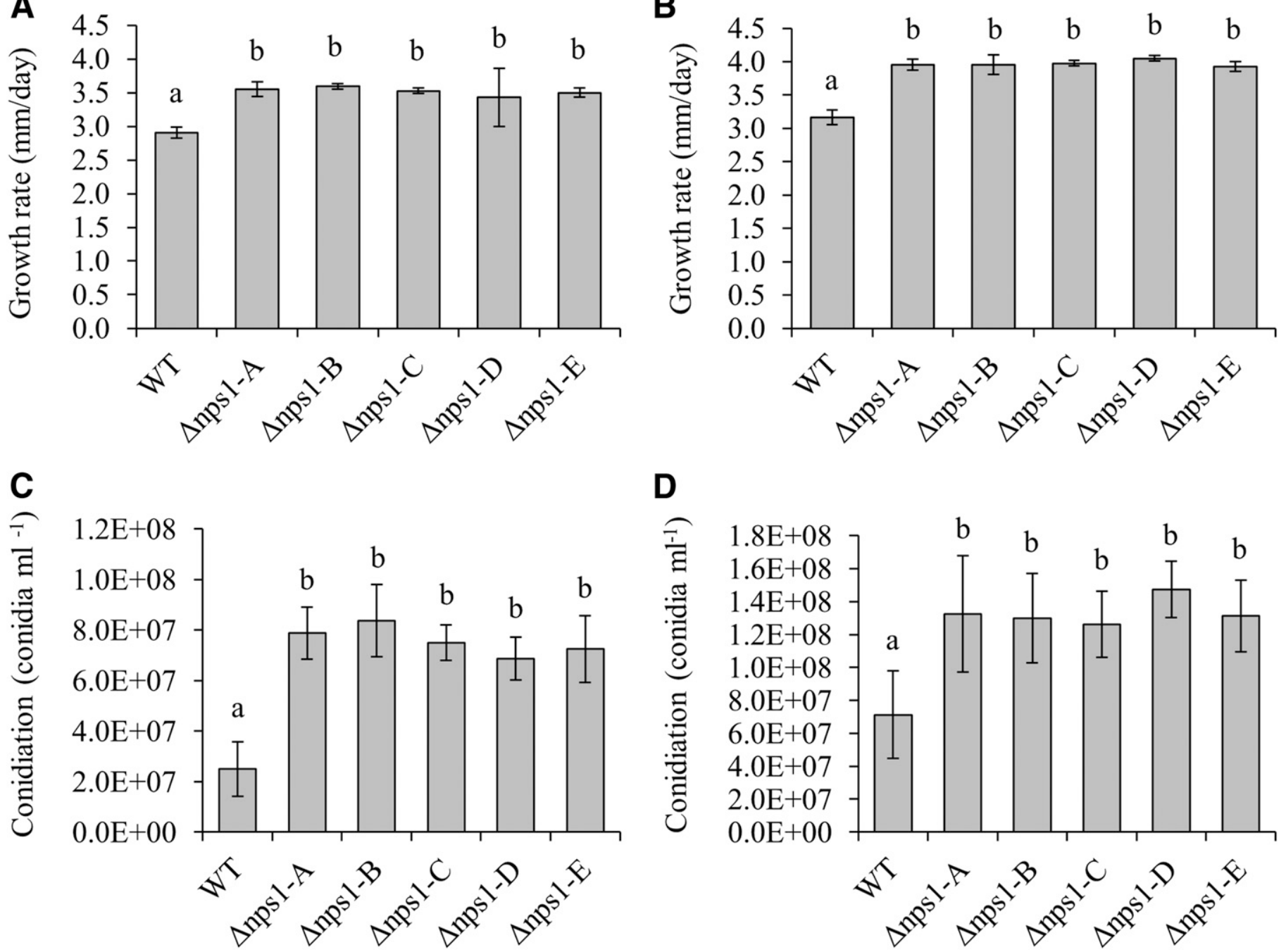

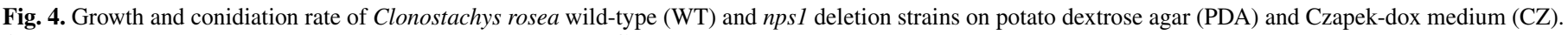

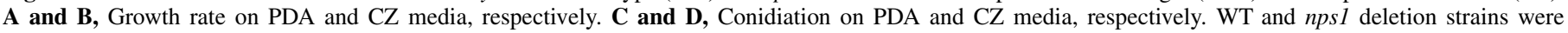

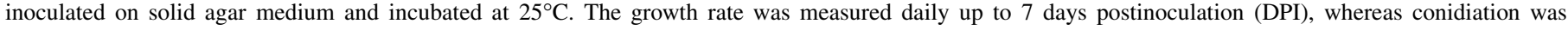

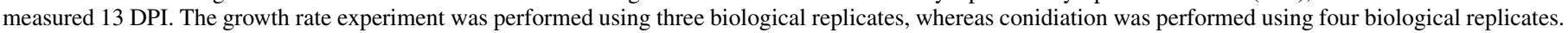

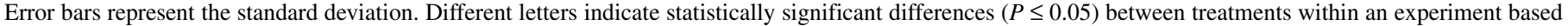
on the Tukey-Kramer test. 
nematodes, which suggested that plant-parasitic nematodes are particularly sensitive to certain metabolites or proteins secreted by C. rosea. This effect has been reported not only for metabolites and proteins secreted by $C$. rosea (Iqbal et al. 2018b) but also for Fusarium oxysporum (Hallmann and Sikora 1996) and Purpureocillium lilacinum (previously Paecilomyces lilacinus) (Cayrol et al. 1989). Our in vitro and in planta data are consistent with the possibility that the NPS1 biosynthesis pathway is directly involved in producing compounds with specificity toward plant-parasitic nematodes. However, this hypothesis requires the identification of the NPS1 product metabolite(s) for validation.

An in planta bioassay showed that the $n p s l$ gene is required for efficient biocontrol of Fusarium foot rot disease on wheat caused by $F$. graminearum. Previously, the lower growth rate of $C$. rosea

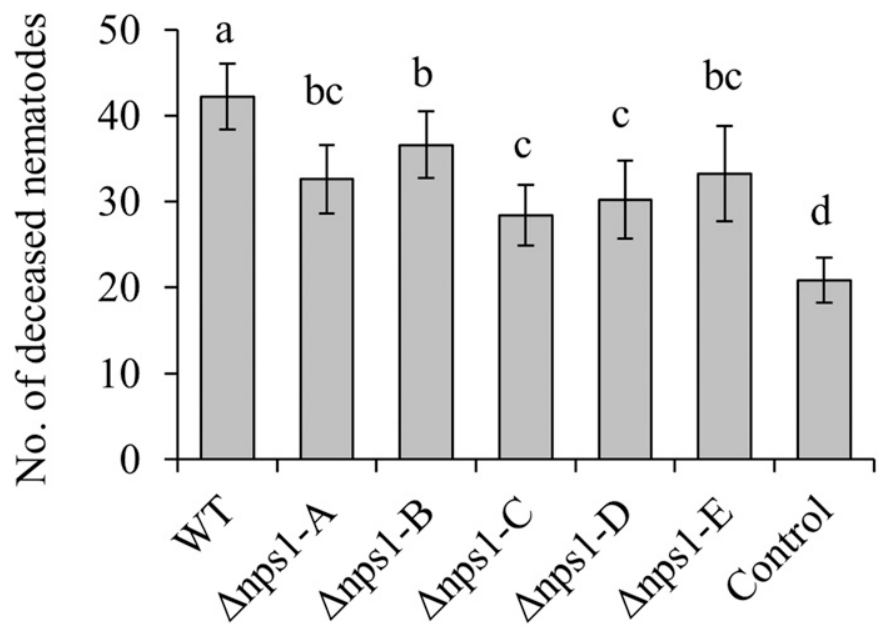

Fig. 5. Nematode mortality in culture filtrates of Clonostachys rosea wild type (WT) and nps 1 deletion strains in potato dextrose broth. Nematode mortality was assessed in culture filtrates from $C$. rosea WT, $\Delta$ nps 1 strains, and in a control medium after $24 \mathrm{~h}$ of incubation at $25^{\circ} \mathrm{C}$. Error bars represent the standard deviation based on five biological replicates. Different letters indicate a statistically significant difference $(P \leq 0.05)$ between treatments as determined by Fisher's least significant difference test.

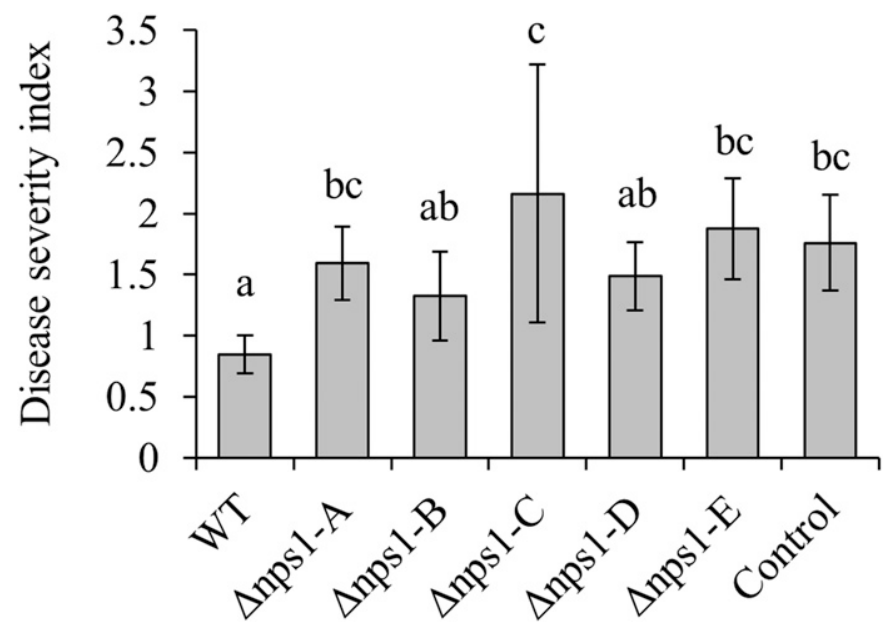

Fig. 6. In planta bioassay to test the biocontrol efficacy of Clonostachys rosea wild-type (WT) and nps1 deletion strains against Fusarium graminearum foot rot disease on wheat. Wheat seeds were coated with $C$. rosea conidia (WT or $\Delta n p s 1$ strains) and planted in moist sand together with an $F$. graminearum agar plug. Seedlings were harvested 3 weeks postinoculation, and disease symptoms were scored on a scale of 0 to 4 . Error bars represent the standard deviation based on five biological replicates. Each replicate comprised the mean of 12 to 15 plants. Different letters indicate statistically significant differences $(P \leq 0.05)$ between treatments based on Fisher's least significant difference test.

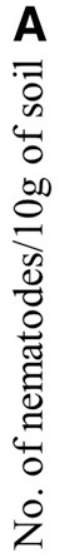

A
$=$
0
4
0
0
0
0
0
0
0
0
0
0
0
0
0
$Z$

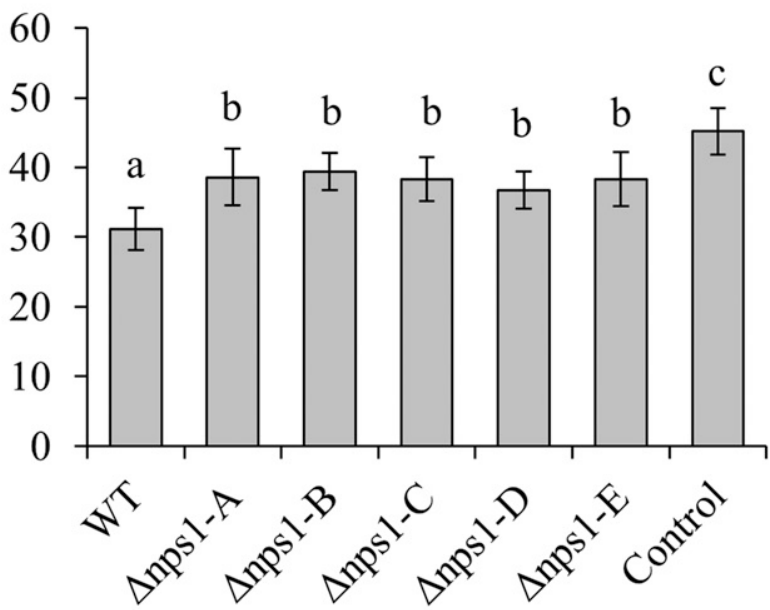

B

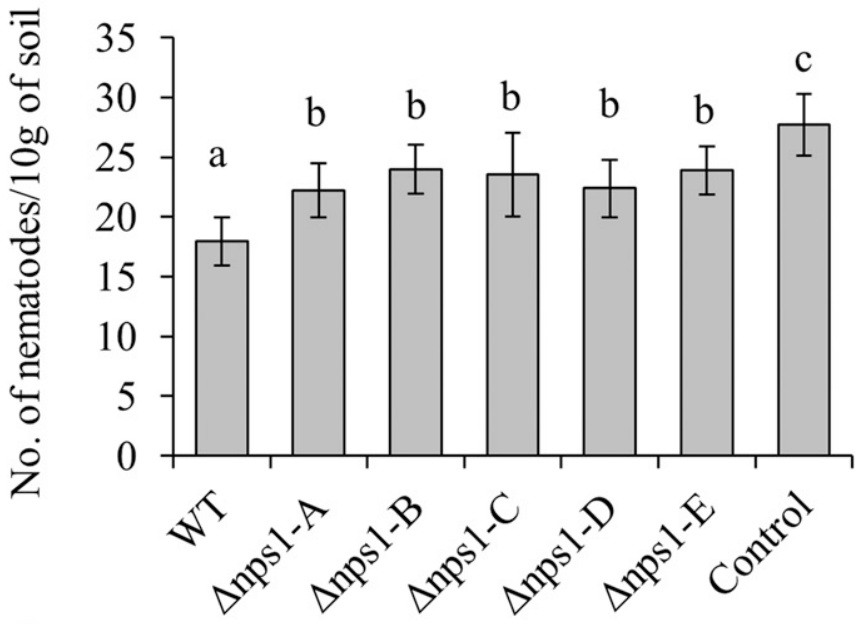

C
$=7$
0
0
4
0
0
0
0
0
0
0
0
0
0
0
0
0
0

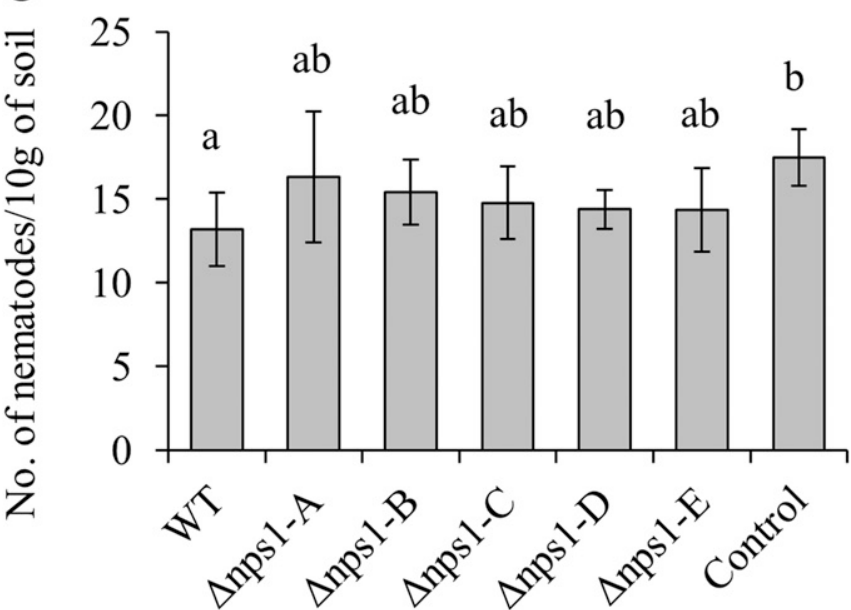

Fig. 7. Effect of Clonostachys rosea wild-type (WT) and nps 1 deletion strains on nematode populations recovered from soil planted with wheat. A, Effects of soil applications of $C$. rosea WT and $\Delta n p s 1$ strains on the overall nematode population recovered from soil, including plant-parasitic nematode genera (Pratylenchus, Rotylenchus, Helicotylenchus, Tylenchorhynchus, Merlinus, Boleodorus, Heterodera $\left[\mathrm{J}_{2}\right]$, and Paratylenchus), and other trophic groups (bacterivores, fungivores, and omnivores). B, Effect on plant-parasitic nematode genera. $\mathbf{C}$, Impact on other trophic groups recovered from the soil. The control treatment corresponds to soil without $C$. rosea application. Error bars represent the standard deviation based on eight biological replicates. Different letters indicate statistically significant differences $(P \leq 0.05)$ between treatments as determined by Fisher's least significant difference for $\mathbf{B}$ and by the Tukey-Kramer test for $\mathbf{A}$ and $\mathbf{C}$. 


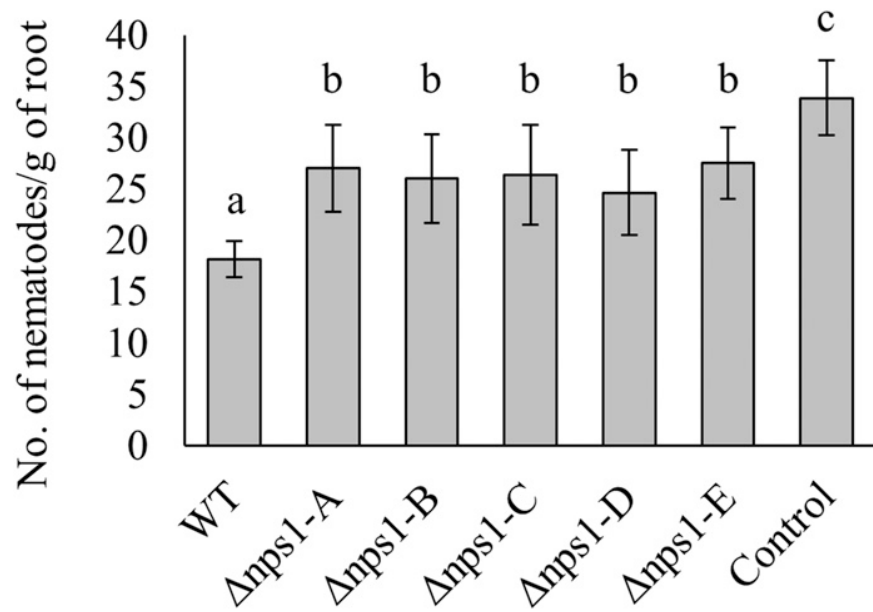

Fig. 8. Effect of Clonostachys rosea wild-type (WT) and nps1 deletion strains on nematode populations recovered from wheat roots. The data include both migratory endoparasitic nematodes from the genus Pratylenchus and endoparasitic nematodes from the genus Heterodera $\left(\mathrm{J}_{2}\right)$. The control treatment corresponds to plants grown in soil without $C$. rosea application. Error bars represent the standard deviation based on eight biological replicates. Different letters indicate statistically significant differences $(P \leq 0.05)$ between treatments as determined by the Tukey-Kramer test.
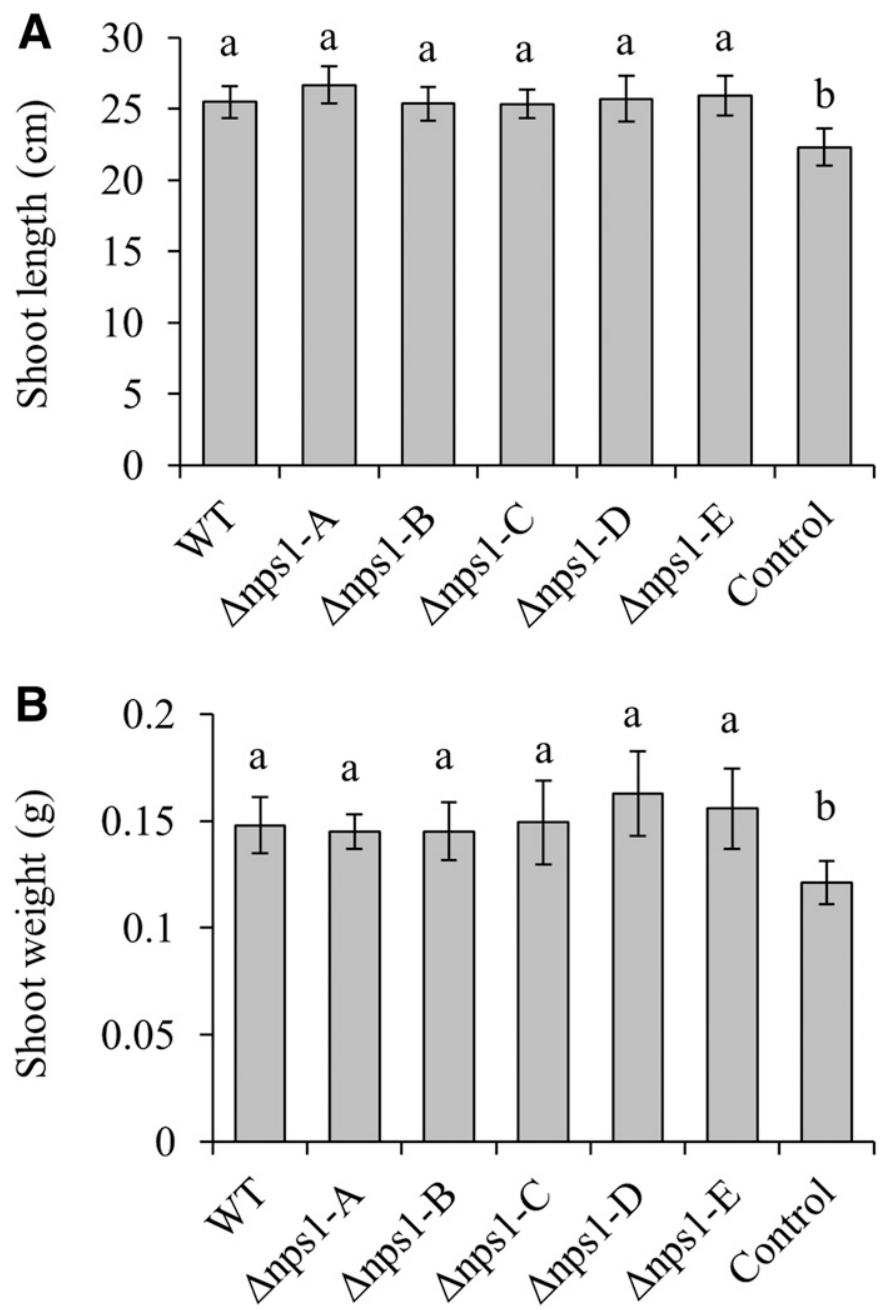

Fig. 9. Effect of soil applications of Clonostachys rosea wild-type (WT) and nps1 deletion strains on shoot length and shoot weight of wheat. A, Average shoot length $(\mathrm{cm})$ and $\mathbf{B}$, average dry shoot weight $(\mathrm{g})$ of plants grown in soil treated with C. rosea WT or Anps1 strains or in soil that was not treated with $C$. rosea application (control). Error bars represent the standard deviation based on eight biological replicates. Different letters indicate statistically significant differences $(P \leq 0.05)$ between treatments as determined by the Tukey-Kramer test. zearalenone lactonohydrolase $z h d 101$ gene deletion strains partially explained a reduction in biocontrol activity (Kosawang et al. 2014). However, because $\Delta n p s 1$ strains display a higher, not lower, growth rate on solid media than the WT, it is more likely that the reduced biocontrol efficiency depends on the inability to produce a metabolite with fungal growth inhibitory activity. Similar results have been reported by Fatema et al. (2018), who showed that deletion of the pks29 polyketide synthase gene in $C$. rosea reduced the biocontrol ability of $C$. rosea toward $F$. graminearum, resulting in increased disease severity in barley. NRPS genes are also involved in the virulence of several different plant pathogenic fungi, including nps6 in C. heterostrophus (Lee et al. 2005), AMT in Alternaria alternata (Johnson et al. 2000), HTS1 in Cochliobolus carbonum (Panaccione et al. 1992), and esynl in Fusarium scirpi, and in other Fusarium species (Haese et al. 1993; Herrmann et al. 1996). Certain NRPS genes also encode NRPs that act as siderophores, thereby influencing virulence. Deletion of the nps 1 gene in $F$. graminearum resulted in mutant strains that were incapable of producing the extracellular ferrichrome-type siderophore malonichrome, with negative consequences for sexual development and virulence (Emery 1980; Oide et al. 2015).

Our results concerning the ability of $C$. rosea to control plantparasitic nematodes are in accordance with previous findings that showed that $C$. rosea decreased the number of plant-parasitic nematodes by 40 to $70 \%$ when applied to soil, which resulted in increased growth of wheat and carrot (Iqbal et al. 2018b). Iqbal et al. (2018b) further showed that $C$. rosea did not reduce the populations of bacterivore, fungivore, or omnivore nematodes in soil, which was in contrast with the results of this study. One explanation for this discrepancy may be the notable difference in the proportion of plant-parasitic nematodes present in the soil used by the two studies compared with the proportion of nonparasitic nematodes; in this study, $73 \%$ of the nematodes were nonparasitic compared with $36 \%$ in the study by Iqbal et al. (2018b).

Deletion of the nps 1 gene reduced the ability of $C$. rosea to control plant-parasitic nematodes in soil and roots of wheat, showing that NPS1 is a biocontrol factor against both fungal and nematode diseases. Previously, the $\mathrm{PrC}$ serine protease, the $\mathrm{PacC}$ transcription factor for $\mathrm{pH}$-dependent gene expression, and several epipolysulfanyldioxopiperazine compounds produced by $C$. rosea have been reported as virulence factors against nematodes based on in vitro assays (Dong et al. 2005; Li et al. 2006; Zou et al. 2010a,b). However, the reduced biocontrol ability of $\Delta n p s 1$ strains was not accompanied by a reduction in wheat seedling growth. This may have been attributable to the relatively low proportion of plantparasitic nematodes in the soil used for the experiment, as already mentioned, or to a plant growth promotion effect of $C$. rosea (Ravnskov et al. 2006; Roberti et al. 2008) that is mechanistically separated from that of NPS1.

In summary, we demonstrated that the $n p s 1$ gene product influences growth and conidiation, in vitro antagonism, and biocontrol of Fusarium foot rot disease and nematode root disease in wheat. This study further emphasized the role of secondary metabolites in determining the outcomes of microbial biocontrol interactions.

\section{ACKNOWLEDGMENTS}

We thank Annika Gustafsson for preparing the $C$. rosea formulations.

\section{LITERATURE CITED}

Baermann, G. 1917. Eine einfache methode zur auffindung von Ancylostomum (Nematoden) larven in erdproben. Geneeskunding Tijdschr. Nederlandsch-Indie 57:131-137.

Bushley, K. E., and Turgeon, B. G. 2010. Phylogenomics reveals subfamilies of fungal nonribosomal peptide synthetases and their evolutionary relationships. BMC Evol. Biol. 10:26.

Calvo, A. M., Wilson, R. A., Bok, J. W., and Keller, N. P. 2002. Relationship between secondary metabolism and fungal development. Microbiol. Mol. Biol. Rev. 66:447-459. 
Cayrol, J.-C., Djian, C., and Pijarowski, L. 1989. Study of the nematicidal properties of the culture filtrate of the nematophagous fungus Paecilomyces lilacinus. Rev. Nematol. 12:331-336.

Challis, G. L., Ravel, J., and Townsend, C. A. 2000. Predictive, structure-based model of amino acid recognition by nonribosomal peptide synthetase adenylation domains. Chem. Biol. 7:211-224.

Chong, J., Soufan, O., Li, C., Caraus, I., Li, S., Bourque, G., Wishart, D. S., and Xia, J. 2018. MetaboAnalyst 4.0: towards more transparent and integrative metabolomics analysis. Nucleic Acids Res.: W486-W494.

Conti, E., Stachelhaus, T., Marahiel, M. A., and Brick, P. 1997. Structural basis for the activation of phenylalanine in the non-ribosomal biosynthesis of gramicidin S. EMBO J. 16:4174-4183.

Decraemer, W., and Hunt, D. J. 2013. Structure and classification. Pages 3-39. In: Plant Nematology, 2nd Ed. R. N. Perry and M. Moens, eds. CABI Publisher, Wallingford, England.

Dong, J.-Y., He, H.-P., Shen, Y.-M., and Zhang, K.-Q. 2005. Nematicidal epipolysulfanyldioxopiperazines from Gliocladium roseum. J. Nat. Prod. 68:1510-1513.

Dubey, M., Jensen, D. F., and Karlsson, M. 2016. The ABC transporter ABCG29 is involved in $\mathrm{H}_{2} \mathrm{O}_{2}$ tolerance and biocontrol traits in the fungus Clonostachys rosea. Mol. Genet. Genomics 291:677-686.

Dubey, M. K., Broberg, A., Jensen, D. F., and Karlsson, M. 2013a. Role of the methylcitrate cycle in growth, antagonism and induction of systemic defence responses in the fungal biocontrol agent Trichoderma atroviride. Microbiology 159:2492-2500.

Dubey, M. K., Broberg, A., Sooriyaarachchi, S., Ubhayasekera, W., Jensen, D. F., and Karlsson, M. 2013b. The glyoxylate cycle is involved in pleotropic phenotypes, antagonism and induction of plant defence responses in the fungal biocontrol agent Trichoderma atroviride. Fungal Genet. Biol. 5859:33-41.

Dubey, M. K., Jensen, D. F., and Karlsson, M. 2014. An ATP-binding cassette pleiotropic drug transporter protein is required for xenobiotic tolerance and antagonism in the fungal biocontrol agent Clonostachys rosea. Mol. PlantMicrobe Interact. 27:725-732.

Dubey, M. K., Ubhayasekera, W., Sandgren, M., Funck Jensen, D., and Karlsson, M. 2012. Disruption of the Eng18B ENGase gene in the fungal biocontrol agent Trichoderma atroviride affects growth, conidiation and antagonistic Ability. PLoS One 7:e36152.

Emery, T. 1980. Malonichrome, a new iron chelate from Fusarium roseum. Biochim. Biophys. Acta 629:382-390.

Fatema, U., Broberg, A., Jensen, D. F., Karlsson, M., and Dubey, M. 2018. Functional analysis of polyketide synthase genes in the biocontrol fungus Clonostachys rosea. Sci. Rep. 8:15009.

Finking, R., and Marahiel, M. A. 2004. Biosynthesis of nonribosomal peptides. Annu. Rev. Microbiol. 58:453-488.

Gan, Z., Yang, J., Tao, N., Yu, Z., and Zhang, K.-Q. 2007. Cloning and expression analysis of a chitinase gene Crchil from the mycoparasitic fungus Clonostachys rosea (syn. Gliocladium roseum). J. Microbiol. 45: 422-430.

Gardiner, D. M., and Howlett, B. J. 2005. Bioinformatic and expression analysis of the putative gliotoxin biosynthetic gene cluster of Aspergillus fumigatus. FEMS Microbiol. Lett. 248:241-248.

Gill, M. S., Olsen, A., Sampayo, J. N., and Lithgow, G. J. 2003. An automated high-throughput assay for survival of the nematode Caenorhabditis elegans. Free Radic. Biol. Med. 35:558-565.

Grünewald, J., and Marahiel, M. A. 2006. Chemoenzymatic and templatedirected synthesis of bioactive macrocyclic peptides. Microbiol. Mol. Biol. Rev. 70:121-146.

Haese, A., Schubert, M., Herrmann, M., and Zocher, R. 1993. Molecular characterization of the enniatin synthetase gene encoding a multifunctional enzyme catalysing $\mathrm{N}$-methyldepsipeptide formation in Fusarium scirpi. Mol. Microbiol. 7:905-914.

Hahn, J., and Dubnau, D. 1991. Growth stage signal transduction and the requirements for srfA induction in development of competence. J. Bacteriol. 173:7275-7282.

Hallmann, J., and Sikora, R. A. 1996. Toxicity of fungal endophyte secondary metabolites to plant parasitic nematodes and soil-borne plant pathogenic fungi. Eur. J. Plant Pathol. 102:155-162.

Herrmann, M., Zocher, R., and Haese, A. 1996. Effect of disruption of the enniatin synthetase gene on the virulence of Fusarium avenaceum. Mol. Plant-Microbe Interact. 9:226-232.

Hue, A., Voldeng, H., Savard, M., Fedak, G., Tian, X., and Hsiang, T. 2009. Biological control of fusarium head blight of wheat with Clonostachys rosea strain ACM941. Can. J. Plant Pathol. 31:169-179.

Hunt, D. J., Palomares-Rius, J. E., and Manzanilla-López, R. H. 2018. Identification, morphology and biology of plant parasitic nematodes. Pages 20-61 in: Plant Parasitic Nematodes in Subtropical and Tropical Agriculture, 3rd ed. R. Sikora, D. Coyne, J. Hallmann, and P. Timper, eds. CABI Publisher, Wallingford, England.
Iqbal, M., Dubey, M., Gudmundsson, M., Viketoft, M., Jensen, D. F., and Karlsson, M. 2018a. Comparative evolutionary histories of fungal proteases reveal gene gains in the mycoparasitic and nematode-parasitic fungus Clonostachys rosea. BMC Evol. Biol. 18:171.

Iqbal, M., Dubey, M., McEwan, K., Menzel, U., Franko, M. A., Viketoft, M., Jensen, D. F., and Karlsson, M. 2018b. Evaluation of Clonostachys rosea for control of plant-parasitic nematodes in soil and in roots of carrot and wheat. Phytopathology 108:52-59.

Jensen, B., Knudsen, I. M., and Jensen, D. F. 2000. Biological seed treatment of cereals with fresh and long-term stored formulations of Clonostachys rosea: Biocontrol efficacy against Fusarium culmorum. Eur. J. Plant Pathol. 106:233-242.

Jensen, B., Knudsen, I. M., and Jensen, D. F. 2002. Survival of conidia of Clonostachys rosea on stored barley seeds and their biocontrol efficacy against seed-borne Bipolaris sorokiniana. Biocontrol Sci. Technol. 12:427-441.

Jensen, B., Knudsen, I. M., Madsen, M., and Jensen, D. F. 2004. Biopriming of infected carrot seed with an antagonist, Clonostachys rosea, selected for control of seedborne Alternaria spp. Phytopathology 94:551-560.

Jensen, D. F., Knudsen, I. M., Mamarabadi, M., Hockenhull, J., and Jensen, B. 2007. Development of a biocontrol agent for plant disease control with special emphasis on the near commercial fungal antagonist Clonostachys rosea strain 'IK726'. Australas. Plant Pathol. 36:95-101.

Johnson, R. D., Johnson, L., Itoh, Y., Kodama, M., Otani, H., and Kohmoto, K. 2000. Cloning and characterization of a cyclic peptide synthetase gene from Alternaria alternata apple pathotype whose product is involved in AMtoxin synthesis and pathogenicity. Mol. Plant-Microbe Interact. 13:742-753.

Kamou, N. N., Dubey, M., Tzelepis, G., Menexes, G., Papadakis, E. N., Karlsson, M., Lagopodi, A. L., and Jensen, D. F. 2016. Investigating the compatibility of the biocontrol agent Clonostachys rosea IK726 with prodigiosin-producing Serratia rubidaea S55 and phenazine-producing Pseudomonas chlororaphis ToZa7. Arch. Microbiol. 198:369-377.

Karimi, M., De Meyer, B., and Hilson, P. 2005. Modular cloning in plant cells. Trends Plant Sci. 10:103-105.

Karlsson, M., Durling, M. B., Choi, J., Kosawang, C., Lackner, G., Tzelepis, G. D., Nygren, K., Dubey, M. K., Kamou, N., Levasseur, A., Zapparata, A., Wang, J., Amby, D. B., Jensen, B., Sarrocco, S., Panteris, E., Lagopodi, A. L., Pöggeler, S., Vannacci, G., Collinge, D. B., Hoffmeister, D., Henrissat, B., Lee, Y. H., and Jensen, D. F. 2015. Insights on the evolution of mycoparasitism from the genome of Clonostachys rosea. Genome Biol. Evol. 7:465-480.

Keating, T. A., Ehmann, D. E., Kohli, R. M., Marshall, C. G., Trauger, J. W., and Walsh, C. T. 2001. Chain termination steps in nonribosomal peptide synthetase assembly lines: Directed acyl-S-enzyme breakdown in antibiotic and siderophore biosynthesis. ChemBioChem 2:99-107.

Keating, T. A., Marshall, C. G., and Walsh, C. T. 2000. Reconstitution and characterization of the Vibrio cholerae vibriobactin synthetase from VibB, VibE, VibF, and VibH. Biochemistry 39:15522-15530.

Keating, T. A., Marshall, C. G., Walsh, C. T., and Keating, A. E. 2002. The structure of $\mathrm{VibH}$ represents nonribosomal peptide synthetase condensation, cyclization and epimerization domains. Nat. Struct. Mol. Biol. 9:522-526.

Keating, T. A., and Walsh, C. T. 1999. Initiation, elongation, and termination strategies in polyketide and polypeptide antibiotic biosynthesis. Curr. Opin. Chem. Biol. 3:598-606.

Kim, K. H., Cho, Y., La Rota, M., Cramer, R. A., Jr., and Lawrence, C. B. 2007. Functional analysis of the Alternaria brassicicola non-ribosomal peptide synthetase gene AbNPS 2 reveals a role in conidial cell wall construction. Mol. Plant Pathol. 8:23-39.

Knudsen, I. M. B., Hockenhull, J., and Jensen, D. F. 1995. Biocontrol of seedling diseases of barley and wheat caused by Fusarium culmorum and Bipolaris sorokiniana: Effects of selected fungal antagonists on growth and yield components. Plant Pathol. 44:467-477.

Kosawang, C., Karlsson, M., Vélëz, H., Rasmussen, P. H., Collinge, D. B., Jensen, B., and Jensen, D. F. 2014. Zearalenone detoxification by zearalenone hydrolase is important for the antagonistic ability of Clonostachys rosea against mycotoxigenic Fusarium graminearum. Fungal Biol. 118: 364-373.

Lahlali, R., and Peng, G. 2014. Suppression of clubroot by Clonostachys rosea via antibiosis and induced host resistance. Plant Pathol. 63:447-455.

Le, S. Q., and Gascuel, O. 2008. An improved general amino acid replacement matrix. Mol. Biol. Evol. 25:1307-1320.

Lee, B.-N., Kroken, S., Chou, D. Y., Robbertse, B., Yoder, O., and Turgeon, B. G. 2005. Functional analysis of all nonribosomal peptide synthetases in Cochliobolus heterostrophus reveals a factor, NPS6, involved in virulence and resistance to oxidative stress. Eukaryot. Cell 4:545-555.

Letunic, I., and Bork, P. 2018. 20 years of the SMART protein domain annotation resource. Nucleic Acids Res.: D493-D496.

Li, G., Huang, H., Kokko, E., and Acharya, S. 2002. Ultrastructural study of mycoparasitism of Gliocladium roseum on Botrytis cinerea. Bot. Bull. Acad. Sin. 43:211-218. 
Li, J., Yang, J., Huang, X., and Zhang, K.-Q. 2006. Purification and characterization of an extracellular serine protease from Clonostachys rosea and its potential as a pathogenic factor. Process Biochem. 41:925-929.

Livak, K. J., and Schmittgen, T. D. 2001. Analysis of relative gene expression data using real-time quantitative PCR and the $2^{-\Delta \Delta C T}$ Method. Methods 25:402-408.

Lorito, M., Peterbauer, C., Hayes, C. K., and Harman, G. E. 1994. Synergistic interaction between fungal cell wall degrading enzymes and different antifungal compounds enhances inhibition of spore germination. Microbiology 140:623-629.

Lorito, M., Woo, S., D’ambrosio, M., Harman, G., Hayes, C., Kubicek, C. P., and Scala, F. 1996. Synergistic interaction between cell wall degrading enzymes and membrane affecting compounds. Mol. Plant-Microbe Interact. 9:206-213.

Lysøe, E., Dees, M. W., and Brurberg, M. B. 2017. A three-way transcriptomic interaction study of a biocontrol agent (Clonostachys rosea), a fungal pathogen (Helminthosporium solani), and a potato host (Solanum tuberosum). Mol. Plant-Microbe Interact. 30:646-655.

Mamarabadi, M., Jensen, B., Jensen, D. F., and Lübeck, M. 2008. Real-time RT-PCR expression analysis of chitinase and endoglucanase genes in the three-way interaction between the biocontrol strain Clonostachys rosea IK726, Botrytis cinerea and strawberry. FEMS Microbiol. Lett. 285: 101-110.

Marahiel, M. A., Stachelhaus, T., and Mootz, H. D. 1997. Modular peptide synthetases involved in nonribosomal peptide synthesis. Chem. Rev. 97: 2651-2674.

Marchler-Bauer, A., Bo, Y., Han, L., He, J., Lanczycki, C. J., Lu, S., Chitsaz, F., Derbyshire, M. K., Geer, R. C., and Gonzales, N. R. 2017. CDD/ SPARCLE: Functional classification of proteins via subfamily domain architectures. Nucleic Acids Res.: D200-D203.

May, J. J., Kessler, N., Marahiel, M. A., and Stubbs, M. T. 2002. Crystal structure of DhbE, an archetype for aryl acid activating domains of modular nonribosomal peptide synthetases. Proc. Natl. Acad. Sci. 99:12120-12125.

Mootz, H. D., Schwarzer, D., and Marahiel, M. A. 2002. Ways of assembling complex natural products on modular nonribosomal peptide synthetases. ChemBioChem 3:490-504.

Mouekouba, L. D. O., Zhang, L., Guan, X., Chen, X., Chen, H., Zhang, J., Zhang, J., Li, J., Yang, Y., and Wang, A. 2014. Analysis of Clonostachys rosea-induced resistance to tomato gray mold disease in tomato leaves. PLoS One 9:e102690.

Mukherjee, P. K., Buensanteai, N., Moran-Diez, M. E., Druzhinina, I. S., and Kenerley, C. M. 2012. Functional analysis of non-ribosomal peptide synthetases (NRPSs) in Trichoderma virens reveals a polyketide synthase (PKS)/NRPS hybrid enzyme involved in the induced systemic resistance response in maize. Microbiology 158:155-165.

Nielsen, H. 2017. Predicting secretory proteins with SignalP. Pages 59-73. In: Protein function prediction: methods and protocols in molecular biology. D. Kihara, ed. Springer, New York, NY.

Nygren, C. M., Eberhardt, U., Karlsson, M., Parrent, J. L., Lindahl, B. D., and Taylor, A. F. 2008. Growth on nitrate and occurrence of nitrate reductaseencoding genes in a phylogenetically diverse range of ectomycorrhizal fungi. New Phytol. 180:875-889.

Nygren, K., Dubey, M., Zapparata, A., Iqbal, M., Tzelepis, G. D., Durling, M. B., Jensen, D. F., and Karlsson, M. 2018. The mycoparasitic fungus Clonostachys rosea responds with both common and specific gene expression during interspecific interactions with fungal prey. Evol. Appl. 11:931-949.

Oide, S., Berthiller, F., Wiesenberger, G., Adam, G., and Turgeon, B. G. 2015. Individual and combined roles of malonichrome, ferricrocin, and TAFC siderophores in Fusarium graminearum pathogenic and sexual development. Front. Microbiol. 5:759.

Oide, S., Krasnoff, S. B., Gibson, D. M., and Turgeon, B. G. 2007. Intracellular siderophores are essential for ascomycete sexual development in heterothallic Cochliobolus heterostrophus and homothallic Gibberella zeae. Eukaryot. Cell 6:1339-1353.

Oide, S., Moeder, W., Krasnoff, S., Gibson, D., Haas, H., Yoshioka, K., and Turgeon, B. G. 2006. NPS6, encoding a nonribosomal peptide synthetase involved in siderophore-mediated iron metabolism, is a conserved virulence determinant of plant pathogenic ascomycetes. Plant Cell 18: 2836-2853.

Pachenari, A., and Dix, N. 1980. Production of toxins and wall degrading enzymes by Gliocladium roseum. Trans. Br. Mycol. Soc. 74:561-566.

Panaccione, D. G., Scott-Craig, J. S., Pocard, J. A., and Walton, J. D. 1992. A cyclic peptide synthetase gene required for pathogenicity of the fungus Cochliobolus carbonum on maize. Proc. Natl. Acad. Sci. 89:6590-6594.

Patron, N. J., Waller, R. F., Cozijnsen, A. J., Straney, D. C., Gardiner, D. M., Nierman, W. C., and Howlett, B. J. 2007. Origin and distribution of epipolythiodioxopiperazine (ETP) gene clusters in filamentous ascomycetes. BMC Evol. Biol. 7:174

Quandt, C. A., Di, Y., Elser, J., Jaiswal, P., and Spatafora, J. W. 2016. Differential expression of genes involved in host recognition, attachment, and degradation in the mycoparasite Tolypocladium ophioglossoides. G3 (Bethesda) 6:731-741.

Ravnskov, S., Jensen, B., Knudsen, I. M., Bødker, L., Jensen, D. F., Karliński, L., and Larsen, J. 2006. Soil inoculation with the biocontrol agent Clonostachys rosea and the mycorrhizal fungus Glomus intraradices results in mutual inhibition, plant growth promotion and alteration of soil microbial communities. Soil Biol. Biochem. 38:3453-3462.

Reiber, K., Reeves, E. P., Neville, C. M., Winkler, R., Gebhardt, P., Kavanagh, K., and Doyle, S. 2005. The expression of selected non-ribosomal peptide synthetases in Aspergillus fumigatus is controlled by the availability of free iron. FEMS Microbiol. Lett. 248:83-91.

Roberti, R., Veronesi, A., Cesari, A., Cascone, A., Di Berardino, I., Bertini, L., and Caruso, C. 2008. Induction of PR proteins and resistance by the biocontrol agent Clonostachys rosea in wheat plants infected with Fusarium culmorum. Plant Sci. 175:339-347.

Rodríguez, M. A., Cabrera, G., Gozzo, F., Eberlin, M., and Godeas, A. 2011. Clonostachys rosea BAFC3874 as a Sclerotinia sclerotiorum antagonist: Mechanisms involved and potential as a biocontrol agent. J. Appl. Microbiol. 110:1177-1186.

Schaeffer, P. 1969. Sporulation and the production of antibiotics, exoenzymes, and exotonins. Bacteriol. Rev. 33:48-71.

Schirmböck, M., Lorito, M., Wang, Y.-L., Hayes, C. K., Arisan-Atac, I., Scala, F., Harman, G. E., and Kubicek, C. P. 1994. Parallel formation and synergism of hydrolytic enzymes and peptaibol antibiotics, molecular mechanisms involved in the antagonistic action of Trichoderma harzianum against phytopathogenic fungi. Appl. Environ. Microbiol. 60:4364-4370.

Schroers, H.-J., Samuels, G. J., Seifert, K. A., and Gams, W. 1999. Classification of the mycoparasite Gliocladium roseum in Clonostachys as C. rosea, its relationship to Bionectria ochroleuca, and notes on other Gliocladium-like fungi. Mycologia 91:365-385.

Sieber, S. A., and Marahiel, M. A. 2003. Learning from nature's drug factories: Nonribosomal synthesis of macrocyclic peptides. J. Bacteriol. 185:7036-7043.

Smith, C. A., Want, E. J., O'Maille, G., Abagyan, R., and Siuzdak, G. 2006. XCMS: Processing mass spectrometry data for metabolite profiling using nonlinear peak alignment, matching, and identification. Anal. Chem. 78:779-787.

Stachelhaus, T., Mootz, H. D., and Marahiel, M. A. 1999. The specificityconferring code of adenylation domains in nonribosomal peptide synthetases. Chem. Biol. 6:493-505.

Stein, T., Vater, J., Kruft, V., Otto, A., Wittmann-Liebold, B., Franke, P., Panico, M., McDowell, R., and Morris, H. R. 1996. The multiple carrier model of nonribosomal peptide biosynthesis at modular multienzymatic templates. J. Biol. Chem. 271:15428-15435.

Sutton, J. C., Li, D.-W., Peng, G., Yu, H., Zhang, P., and Valdebenito-Sanhueza, R. 1997. Gliocladium roseum a versatile adversary of Botrytis cinerea in crops. Plant Dis. 81:316-328.

Tamura, K., Stecher, G., Peterson, D., Filipski, A., and Kumar, S. 2013. MEGA6: Molecular evolutionary genetics analysis version 6.0. Mol. Biol. Evol. 30:2725-2729.

Tautenhahn, R., Boettcher, C., and Neumann, S. 2008. Highly sensitive feature detection for high resolution LC/MS. BMC Bioinform. 9:504.

Tzelepis, G., Dubey, M., Jensen, D. F., and Karlsson, M. 2015. Identifying glycoside hydrolase family 18 genes in the mycoparasitic fungal species Clonostachys rosea. Microbiology 161:1407-1419.

Usami, Y., Yamaguchi, J., and Numata, A. 2004. Gliocladins A-C and glioperazine; cytotoxic dioxo- or trioxopiperazine metabolites from a Gliocladium sp. separated from a sea hare. Heterocycles 63:1123-1129.

Utermark, J., and Karlovsky, P. 2008. Genetic transformation of filamentous fungi by Agrobacterium tumefaciens. Protocol Exchange.

van den Berg, R. A., Hoefsloot, H. C., Westerhuis, J. A., Smilde, A. K., and van der Werf, M. J. 2006. Centering, scaling, and transformations: improving the biological information content of metabolomics data. BMC Genomics 7:142.

Viketoft, M., Palmborg, C., Sohlenius, B., Huss-Danell, K., and Bengtsson, J. 2005. Plant species effects on soil nematode communities in experimental grasslands. Appl. Soil Ecol. 30:90-103.

Weber, T., Baumgartner, R., Renner, C., Marahiel, M. A., and Holak, T. A. 2000. Solution structure of PCP, a prototype for the peptidyl carrier domains of modular peptide synthetases. Structure 8:407-418.

Yu, H., and Sutton, J. C. 1997. Morphological development and interactions of Gliocladium roseum and Botrytis cinerea in raspberry. Can. J. Plant Pathol. 19:237-246.

Zou, C. G., Tao, N., Liu, W. J., Yang, J. K., Huang, X. W., Liu, X. Y., Tu, H. H., Gan, Z. W., and Zhang, K. Q. 2010b. Regulation of subtilisin-like protease $\operatorname{prC}$ expression by nematode cuticle in the nematophagous fungus Clonostachys rosea. Environ. Microbiol. 12:3243-3252.

Zou, C. G., Tu, H. H., Liu, X. Y., Tao, N., and Zhang, K. Q. 2010a. PacC in the nematophagous fungus Clonostachys rosea controls virulence to nematodes. Environ. Microbiol. 12:1868-1877. 